\title{
Development, validation, and application of the ribosome separation and reconstitution system for protein translation in vitro
}

\author{
BRANDON M. TRAINOR, ${ }^{1,2}$ DIMITRI G. PESTOV ${ }^{1}$ and NATALIA SHCHERBIK ${ }^{1}$ \\ ${ }^{1}$ Department of Cell Biology and Neuroscience, Rowan University, School of Osteopathic Medicine, Stratford, New Jersey 08084, USA \\ ${ }^{2}$ Graduate School of Biomedical Sciences, Rowan University, Stratford, New Jersey 08084, USA
}

\begin{abstract}
Stress-induced molecular damage to ribosomes can impact protein synthesis in cells, but cell-based assays do not provide a clear way to distinguish the effects of ribosome damage from stress responses and damage to other parts of the translation machinery. Here we describe a detailed protocol for the separation of yeast ribosomes from other translational machinery constituents, followed by reconstitution of the translation mixture in vitro. This technique, which we refer to as ribosome separation and reconstitution (RSR), allows chemical modifications of yeast ribosomes without compromising other key translational components. In addition to the characterization of stress-induced ribosome damage, RSR can be applied to a broad range of experimental problems in studies of yeast translation.
\end{abstract}

Keywords: in vitro translation; centrifugation; Saccharomyces cerevisiae; ribosome; ribosome modification

\section{INTRODUCTION}

Cell-free translation systems are powerful experimental assets with a wide variety of applications. They allow protein production in a tightly controlled environment using either endogenous transcripts or mRNA reporters. The generated proteins can then be used in subsequent applications like pull-down assays or analyzed as readouts of translation reactions addressing roles of cis- and trans-acting factors in translation (Carlson et al. 2012; Chong 2014). Additionally, the cell-free translation reaction allows subsequent supplementation with carefully designed additional factors. For example, this approach was instrumental to identifying the order of molecular events in complex cotranslational mechanisms (Shao and Hegde 2014; Kuroha et al. 2018).

Despite all the advantages of cell-free translation systems, they remain insufficient in dissecting the effects of stress on translational executors. In fact, under stressful conditions, various molecules of the translational machinery undergo modifications (Tanaka et al. 2007; Chan et al. 2012; Gu et al. 2014; Simms et al. 2014; Endres et al. 2015; Wu et al. 2018; Yan et al. 2019). Thus, it is impossible to distinguish between a stressor's impact on a partic-

Corresponding author: shcherna@rowan.edu

Article is online at http://www.rnajournal.org/cgi/doi/10.1261/rna. 078852.121. Freely available online through the RNA Open Access option. ular molecule of interest and on other translationally essential elements.

Built of RNAs and proteins, ribosomes are, unsurprisingly, highly susceptible to chemical modifications. Indeed, ribosomes undergo significant modifications when exposed to chemical compounds, metals, or reactive oxygen species (ROS) (for review, see Shcherbik and Pestov 2019). In addition, in response to a variety of stress conditions, ribosomes and ribosome-bound nascent chains are subject to post-translational protein modifications, such as ubiquitination (for review, see Dougherty et al. 2020). How performance of modified ribosomes is altered during protein synthesis remains largely unknown. This shortcoming is primarily due to the unavailability of a suitable experimental platform that would allow modification of ribosomes exclusively while keeping other translationally essential molecules intact.

To overcome this technical limitation, we sought to develop a method for isolating translationally active ribosomes that could be subsequently returned back into translationally active ribosome-free yeast lysate charged with an mRNA reporter (schematics in Fig. 1). This approach allows incorporation of a ribosomal modification step into the procedure, in which ribosomes are exposed

(C) 2021 Trainor et al. This article, published in RNA, is available under a Creative Commons License (Attribution-NonCommercial 4.0 International), as described at http://creativecommons.org/licenses/ by-nc/4.0/. 
A

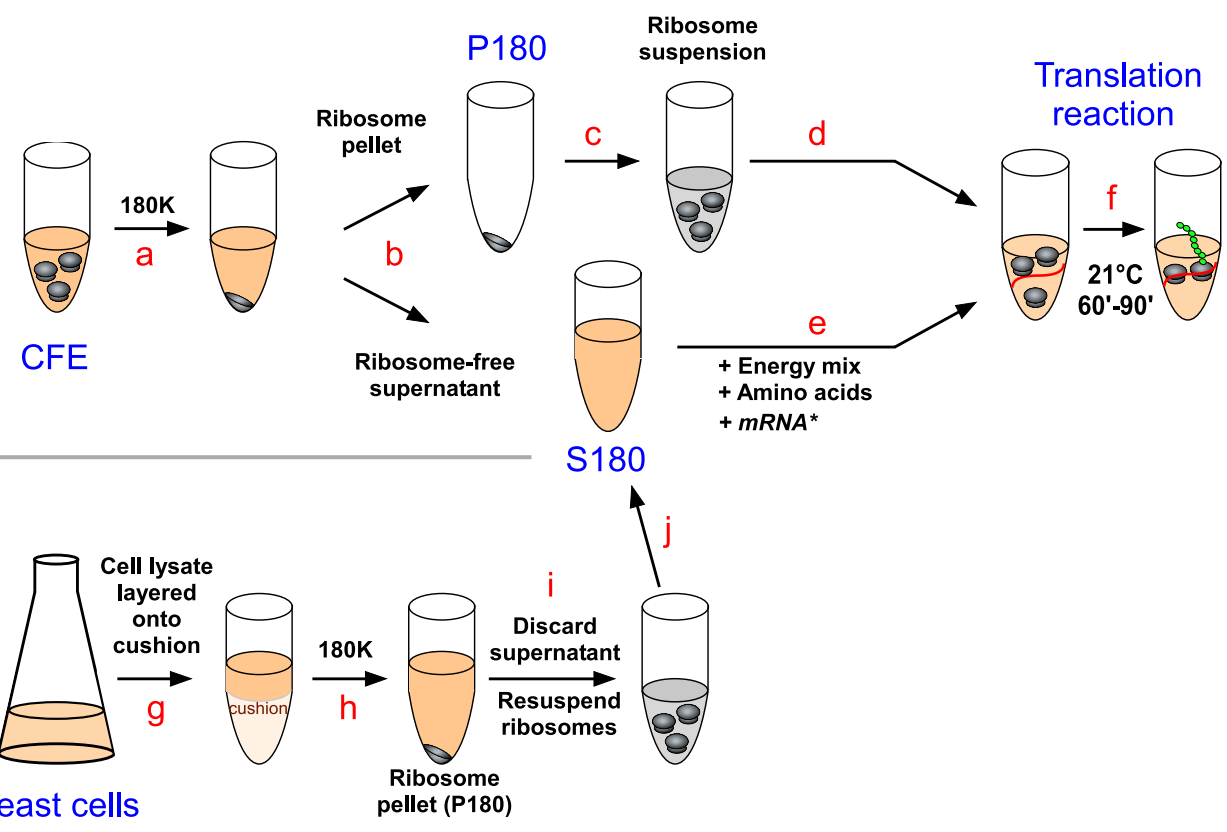

FIGURE 1. Experimental workflow for ribosome separation and reconstitution (RSR). Ribosomes for a cell-free translation reaction can be isolated from a previously prepared CFE $(A)$, or by the direct lysis of yeast cells $(B)$. (a) CFE is ultracentrifuged at $180,000 \mathrm{~g}(180 \mathrm{~K})$ for $2 \mathrm{~h}$ at $4^{\circ} \mathrm{C}$, producing ribosome-containing pellet $\mathrm{P} 180$ and ribosome-free supernatant $\mathrm{S} 180$ (b). Ribosomal pellet P180 is solubilized (c) and added back to S180 (d), along with the energy regeneration system, amino acids, and (optionally) a reporter mRNA (e). Translation reactions are carried out at $21^{\circ} \mathrm{C}$ for $60-$ $90 \mathrm{~min}(\mathrm{f})$. Alternatively, yeast cells are lysed with glass beads, and the clarified cellular lysate is next layered onto a $20 \% \mathrm{glycerol}$ cushion (g); ribosomes are precipitated by centrifugation through the cushion at $180,000 \mathrm{~g}(180 \mathrm{~K})$ for $2 \mathrm{~h}$ at $4^{\circ} \mathrm{C}(\mathrm{h})$. The resulting supernatant is discarded, ribosomal pellet P180 is solubilized (i) and added to the CFE-derived S180 to assemble the translation reaction (j).

to a modifying agent of choice either in vitro or in vivo. The success of this approach depends on the purification of intact and translationally functional ribosomes from the cellfree extract (CFE) or cell culture.

The methodology for isolating ribosomes and ribosomal complexes has been described for different organisms and is fine-tuned to each experiment's goals, which does not always require translational activity of the isolate. Thus, the particular purpose of the isolation dictates the stringency of the ribosome purification protocol. In general, there are two primary strategies to isolate ribosomes, ultracentrifugation and immunoprecipitation (IP), both of which have substantial limitations. Centrifugation-based technology, described by different laboratories, requires lengthy and often numerous spins and, thus, subjects ribosomes to prolonged exposure to ribonucleases and proteases present in crude cellular lysates. Another limitation of centrifugationbased ribosome isolation is the poor solubilization of the resulting ribosomal pellet (Munoz et al. 2017). On the contrary, the IP approach is fast and avoids pelleting, resulting in soluble ribosomes (Oeffinger et al. 2007). However, it demands incorporating a tag on a surface-exposed r-protein, which may interfere with ribosome activities. In addition, the IP approach requires high salt concentrations in the precipitation and elution buffers to avoid pulling down nonspecific molecules, potentially leading to undesirable stripping of ribosomal cofactors that may perform auxiliary roles during translation (Shi et al. 2017; Simsek et al. 2017; Mazaré et al. 2020).

Here, we report an experimental protocol for ribosome separation and reconstitution (RSR) developed for purifying translationally competent ribosomes from Saccharomyces cerevisiae. The purified ribosomes retain their translational competency when supplied back to translationally active, ribosome-free CFE and can synthesize proteins from various $m R N A$ reporters or endogenous transcripts present in the CFE. To the best of our knowledge, a yeast-based RSR-like protocol has never been reported before. Considering that yeast cells can be cultured in large quantities and are very amenable to genetic manipulations, our protocol may provide significant methodological advances to studies of eukaryotic translation, ribosome biology and protein quality control. Because the RSR approach also allows treating ribosomes with a modifying agent of interest under defined conditions in a test tube, it can facilitate studies of diverse types of chemical or physical factors capable of impairing ribosome functionality. In this communication, using the ROS inducer menadione and chemotherapeutic drug cisplatin as two rRNA modifiers with different characteristics, we demonstrate the capabilities of the RSR technique for the analysis of effects of environmental and intracellular ribosome stressors. 


\section{RESULTS}

\section{Establishment and validation of the RSR system}

We have recently developed, validated, and applied a cryogenic lysis-based method to prepare yeast cell-free translation extracts (CFE) capable of protein synthesis from mRNA reporters and endogenous cellular transcripts (Trainor et al. 2021b). To develop a system that allows ribosome separation followed by reconstitution of translation in vitro, we used CFE as a starting platform. We first aimed to purify ribosomes from CFE by one-step ultracentrifugation and assess their quality and activity during protein synthesis in vitro by returning them into translationally active, ribosome-free CFE charged with an mRNA reporter (schematics in Fig. 1A).

\section{Preparation of ribosomes from CFE by one-step ultracentrifugation}

To pellet ribosomes, we centrifuged one aliquot of CFE ( $560 \mu \mathrm{g}$ of RNA, $1590 \mu \mathrm{g}$ of proteins) at $180,000 \mathrm{~g}$ for $2 \mathrm{~h}$ at $4^{\circ} \mathrm{C}$ (Fig. 1-a) in the TLA55 Beckman rotor and collected the supernatant (S180) and pellet (P180) fractions (Fig. 1-b). Pelleted ribosomes were solubilized in translation reaction buffer $\mathrm{A}[20 \mathrm{mM}$ Hepes-KOH, $\mathrm{pH} 7.4 ; 100 \mathrm{mM}$ $\mathrm{KOAc} ; 2 \mathrm{mM} \mathrm{Mg}(\mathrm{OAc})_{2}$; and $2 \mathrm{mM} \mathrm{DTT}$ ) (Fig. 1-c and see below; Wu and Sachs 2014) and analyzed by northern blotting, along with $\mathrm{S} 180$ and complete CFE used as controls. Hybridization with probes specific to 25S rRNA, 18S rRNA, tRNA ${ }^{\mathrm{Val}}$, and tRNA ${ }^{\mathrm{Glu}}$ verified that the two fractions generated by this ultracentrifugation step $(180,000 \mathrm{~g}$ for $2 \mathrm{~h}$; $180 \mathrm{~K}$ centrifugation hereafter) represented the ribosome-free supernatant (S, Fig. 2A, lane 2) and ribosome-enriched pellet ( $P$, Fig. 2A, lane 3). As expected, tRNAs, visible in the complete CFE, cofractionated with the supernatant fraction (Fig. 2A, lanes 1 and 2). rRNAs derived from the pellet fraction revealed no signs of degradation (Fig. 2A), suggesting that $2 \mathrm{~h}$ of centrifugation does not affect rRNA integrity.

\section{Characterization of ribosomes by sucrose gradient centrifugation analysis}

Next, using sucrose gradient centrifugation analysis, we examined which ribosomal species were precipitated during 180K-centrifugation (Fig. 1-a). As a control, we used a CFE sample that was not subjected to ribosome pelleting. Gradients were fractionated into 12 fractions, and RNA was extracted from each fraction and analyzed by northern hybridization with probes specific to $25 \mathrm{~S}$ and $18 \mathrm{~S}$ rRNAs. The gradient analysis showed that ribosomes predominantly accumulated in the 805 fraction, with only residual amounts present on polysomes before and after 180Kcentrifugation (Fig. 2B). These data demonstrate that
$180 \mathrm{~K}$-centrifugation is sufficient to pellet nonpolysomal $80 \mathrm{~S}$ ribosomes.

Interestingly, we also tested sucrose gradient-based ribosome isolation as an alternative approach to the 180Kcentrifugation of the CFE (Supplemental Fig. S1A). In our hands, ribosomes derived by this technique exhibited an increased degree of rRNA degradation and were significantly less active in translation (Supplemental Fig. S1B-D). Thus, we used $180 \mathrm{~K}$-centrifugation in all later experiments as a fast way to recover ribosomes $(2.5 \mathrm{~h}$ total time vs. 7.5-8 h required for gradient-based isolation, Fig. S1D), which preserved well rRNA integrity and translational activity.

\section{Optimizing solubilization of pelleted ribosomes}

In our early trials of the RSR protocol, we found that obtaining a homogeneous suspension of pelleted ribosomes was critical for the reproducibility of the following translation assays. This step was also previously identified as a main limitation of the centrifugation-based ribosome purification approach (Munoz et al. 2017). In fact, we routinely observed that pelleted ribosomes were sticky and difficult to resuspend by pipetting. Due to lack of detailed published information on the resuspension procedure for pelleted ribosomes, we tested the effects of temperature and automated agitation in facilitating ribosomal pellet solubilization. Three CFE-derived ribosomal pellets were incubated in $100 \mu \mathrm{L}$ of buffer $\mathrm{A}$ for $30 \mathrm{~min}$ at $8^{\circ} \mathrm{C}, 21^{\circ} \mathrm{C}$, and $37^{\circ} \mathrm{C}$ with $1200 \mathrm{rpm}$ shaking in Eppendorf thermomixers. Subsequent centrifugation of the ribosomal suspensions at $21,000 \mathrm{~g}$ for $15 \mathrm{~min}$ at $4^{\circ} \mathrm{C}$ did not produce any visible pellets or insoluble debris. The RNA concentrations were similar in all ribosomal suspensions; pellets resuspended at $8^{\circ} \mathrm{C}$ yielded $4.50 \mu \mathrm{g} / \mu \mathrm{L}$ of RNA, pellets resuspended at $21^{\circ} \mathrm{C}$ yielded $4.52 \mu \mathrm{g} / \mu \mathrm{L}$ of RNA, and pellets resuspended at $37^{\circ} \mathrm{C}$ yielded $4.43 \mu \mathrm{g} / \mu \mathrm{L}$ of RNA. Quantifying $18 \mathrm{~S}$ and 25S rRNAs detected by northern hybridization (Fig. 3A) likewise demonstrated similar levels of these rRNAs regardless of the temperature used during solubilization (Fig. 3B). Northern blot analysis also revealed that ribosomes incubated at $8{ }^{\circ} \mathrm{C}, 21^{\circ} \mathrm{C}$, and $37^{\circ} \mathrm{C}$ for 30 min contained intact $25 \mathrm{~S}$ and $18 \mathrm{~S}$ rRNAs with no signs of degradation (Fig. $3 \mathrm{~A})$, arguing that the solubilization step (Fig. 1-c) does not affect rRNA stability.

To examine translational activity of the 180K-pelleted/ solubilized ribosomes, we assembled in vitro translation reactions that contained the ribosome-free extract (S180, Fig. 1-b), $3 \mu \mathrm{g}$ of ribosomes resuspended at different temperatures, amino acids, and the energy-regeneration system (Fig. 1-e-f). Reactions were programmed with 200 ng of TAP-RLuc mRNA reporter (Renilla luciferase gene fused with TAP-tag). We found that ribosomes solubilized at all temperatures tested synthesized TAP-RLuc as determined by quantitative Renilla luciferase assays (Fig. 3C) 


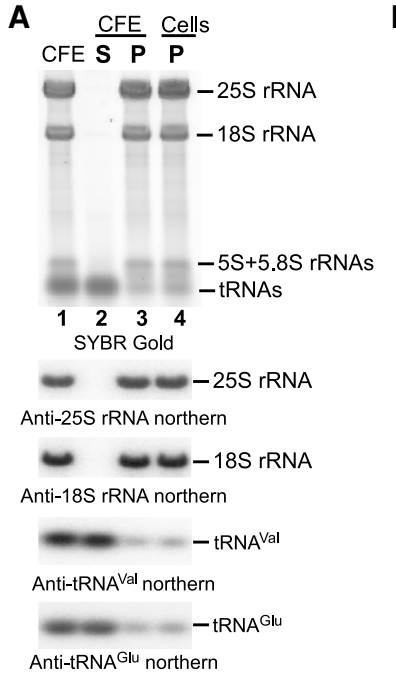

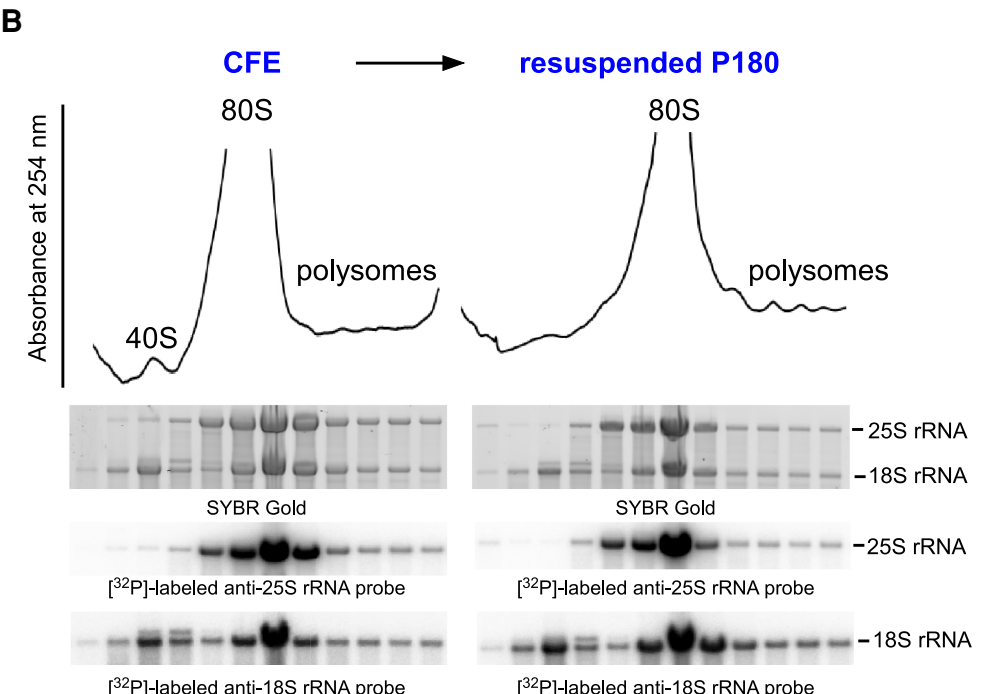

$\left.{ }^{32} \mathrm{P}\right]$-labeled anti-18S rRNA probe

[32P]-labeled anti-18S rRNA probe

C

Cell lysate (glass beads)
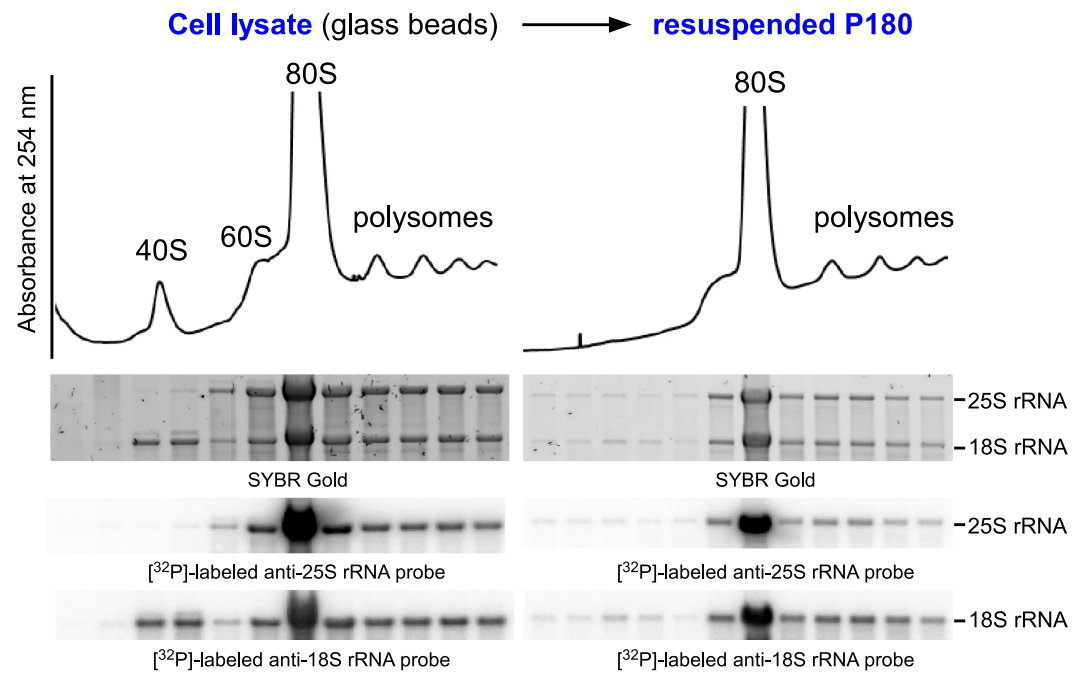

[32P]-labeled anti-25S rRNA probe

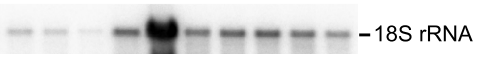

$\left.{ }^{32} \mathrm{P}\right]$-labeled anti-18S rRNA probe

FIGURE 2. Analysis of ribosomes before and after 180K-centrifugation. (A) One-step ultracentrifugation generates stable ribosomes and ribosome-free lysate. Aliquots of complete CFE (CFE), separated S180 and P180 (CFE: S, P), and P180 isolated from cells with glass-bead lysis (Cells: P) were resolved on a denaturing agarose gel and analyzed by northern hybridization with indicated probes. Prior to transfer onto nylon membrane, the gel was stained with SYBR Gold. $(B, C)$ Ribosomes precipitated by one-step ultracentrifugation exist as $80 \mathrm{~S}$ monosomes. (B) Complete CFE and solubilized P180 were centrifuged through $15 \%-45 \%(\mathrm{w} / \mathrm{v})$ sucrose gradients and fractionated with continuous absorbance measurement at $254 \mathrm{~nm}$ to visualize ribosomal peaks. RNA was extracted from individual fractions and analyzed by northern hybridization as described in A. (C) Sucrose gradient centrifugation analysis performed with the total cellular lysate obtained with glass-bead lysis and its resuspended P180.

and confirmed by western blotting (Fig. 3D). However, incubation at $37^{\circ} \mathrm{C}$ reduced translational activity of ribosomes approximately twofold (Fig. 3C). The reduced translation activity of $37^{\circ} \mathrm{C}$-resuspended ribosomes could be explained by irreversible modifications that might occur at $37^{\circ} \mathrm{C}$ or by disassociation of key translation factors (Cox et al. 1973; Danielsson et al. 2015). This result also correlated with poor performance of ribosomes during CFE-based translation at $37^{\circ} \mathrm{C}$, further confirming that this temperature is not optimal for ribosomes extracted from BY4741 cells under low ionic stringency conditions, such as 100 $\mathrm{mM} \mathrm{KOAc}$ and $3 \mathrm{mM} \mathrm{Mg}(\mathrm{OAc})_{2}$ (Pestova et al. 1998;
Algire et al. 2002; Khatter et al. 2014; Wu and Sachs 2014). Based on published literature, this buffer composition appears to be optimal to promote correct folding of rRNAs within the ribosomal structure and provide intersubunit stability (Khatter et al. 2014).

Interestingly, another study demonstrated that translationally active lysates prepared from the yeast background strain GRF-18 resulted in a higher protein yield and faster kinetics of protein synthesis in vitro at $37^{\circ} \mathrm{C}$ than at $25^{\circ} \mathrm{C}$ (Altmann et al. 1989). Therefore, it seems reasonable to propose that different yeast genetic backgrounds might have individual specific temperature requirements. 
A

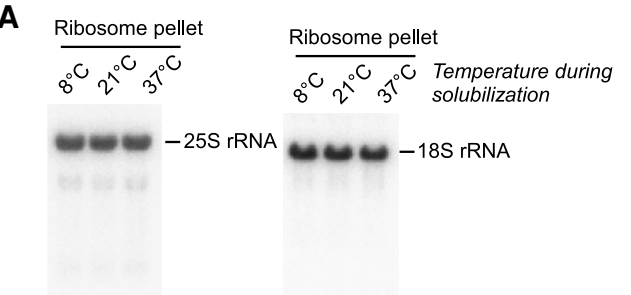

Anti-25S rRNA northern Anti-18S rRNA northern

C

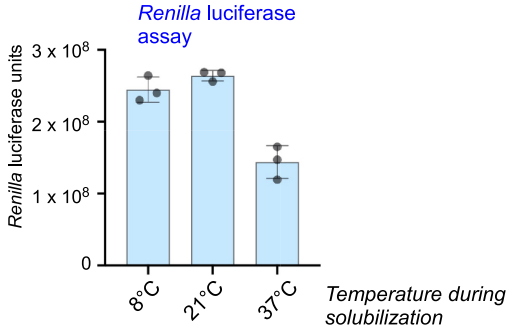

FIGURE 3. Pelleted and solubilized ribosomes retain their translational competency. (A) CFEderived ribosomal pellets $\mathrm{P} 180$ generated as described in Figure 2A were resuspended in buffer A by shaking for 30 min at the indicated temperatures. Resuspended RNA was analyzed by northern hybridization with 25S rRNA and 18S rRNA specific probes. (B) The hybridization signals corresponding to the full-length 25S rRNAs and 18S rRNAs were converted to phosphorimaging units and plotted as bar graphs. The error bars represent standard error of the mean (SEM) of three experiments. The differences between the samples were nonsignificant (NS); statistical analysis was performed by one-way ANOVA. (C) $3 \mu \mathrm{g}$ of resuspended ribosomes were placed into translation reactions containing ribosome-free translational lysate S180 charged with capped TAP-RLuc mRNA (200 ng per reaction). Reaction products were analyzed by the Renilla luciferase assay and the data are presented as bar graphs, wherein error bars represent standard error of the mean (SEM) of three experiments. (D) Proteins and RNA were extracted from the luciferase reactions and further characterized by western blots using anti-TAP antibodies and by northern hybridizations using TAP-specific probe.

Unless using BY4741 or its derivatives, researchers will have to determine the optimal temperature for the in vitro translation reaction and examine temperature requirements for the ribosome solubilization step of the RSR procedure as illustrated in Figure 3C.

Thus, precipitation of ribosomes from a BY4741-derived CFE by one-step centrifugation at $180,000 \mathrm{~g}$ followed by 30 -min shaking in a thermomixer at $8{ }^{\circ} \mathrm{C}-21^{\circ} \mathrm{C}$ recovers well-preserved ribosomes that exhibit high translational activity when combined with a ribosome-free supernatant, allowing for an effective implementation of the RSR approach.

\section{Optimization of the translation reaction}

\section{Reaction time}

Having established P180-ribosome solubilization and buffer composition requirements (Fig. 3A-D), we next examined the kinetics of protein synthesis using the RSR approach in comparison to complete CFE. Identifying time points at which the translated product increases with a steady rate and before the synthesis plateaus is critical for reliably comparing the activity of ribosomes derived from different experimental conditions. We assembled $30 \mu \mathrm{L}$ reactions using either complete CFE or the pelleted, $21^{\circ} \mathrm{C}$-solubilized ribosomes ( $24 \mu \mathrm{g}$ of total RNA from P180) added to ribosome-free extract (S180). Both reactions were charged with $400 \mathrm{ng}$ of capped TAP-RLuc mRNA reporter, and aliquots of the reaction were analyzed every $30 \mathrm{~min}$ for $3 \mathrm{~h}$ using a Renilla luciferase assay (Fig. 4A). To account for the different amounts of ribosomes present in the CFE and RSR reactions, we normalized the Renilla luciferase units by the amounts of $18 \mathrm{~S}$ rRNA present in each reaction. For this normalization, we extracted RNA from each reaction after the luciferase assays were completed and quantified $18 \mathrm{~S}$ rRNA by northern hybridizations and phoshorimaging (Fig. 4A, bottom panels). This analysis revealed that protein synthesis progressed with nonlinear kinetics, with maximum rates achieved during the first 30-90 min for both RSR and CFE-assembled translation reactions (Fig. 4A; Supplemental Fig. S2). Interestingly, we detected a higher yield of TAP-RLuc in the RSR reactions than in the CFE reactions when normalized for the 18S rRNA amount (Fig. 4A). The RLuc signal normalized by $25 \mathrm{~S}$ rRNA was found to follow a similar trend as RLuc/18S (Supplemental Fig. S2B). Although the exact mechanism for this effect remains unclear, the observation that centrifugation and resuspension of ribosomes may alter their activity indicates that it is essential to apply identical separation steps to all ribosomes being compared in order to correctly interpret data from RSR experiments. In addition, these data indicate that the practical timeframe for a translation reaction is limited to $30-90 \mathrm{~min}$ in the present protocol [i.e., $12 \mu \mathrm{g}$ of rRNA (P180) in a $15 \mu \mathrm{L}$ reaction charged with $400 \mathrm{ng}$ of the Renilla luciferase mRNA]. The optimal reaction time should be determined for any new CFE batch and ribosome precipitation/resuspension condition by running control reactions as shown in Figure 4A.

\section{Optimization of the ribosome content}

We next examined the dependency of the translation efficiency on the concentration of ribosomes in a reaction. We assembled $15 \mu \mathrm{L}$ translation reactions with different amounts of ribosomes added to the ribosome-free supernatant S180. These reactions were charged with $200 \mathrm{ng}$ of capped TAP-RLuc mRNA reporter, incubated at $21^{\circ} \mathrm{C}$ for 
A Renilla luciferase signal, normalized by $18 \mathrm{~S}$ rRNA

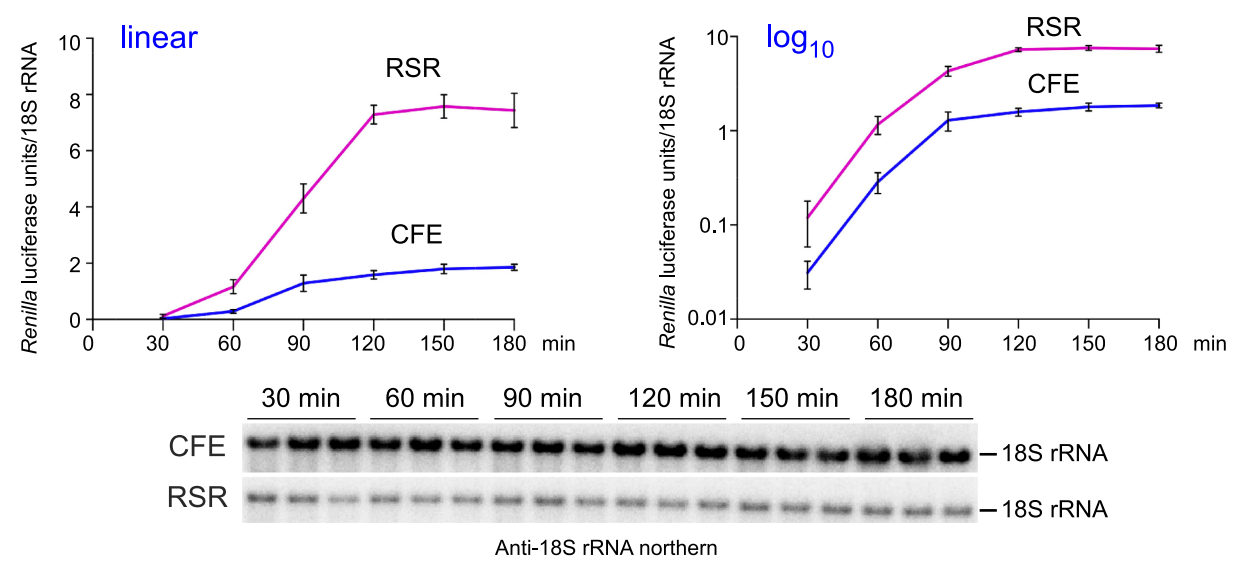

B

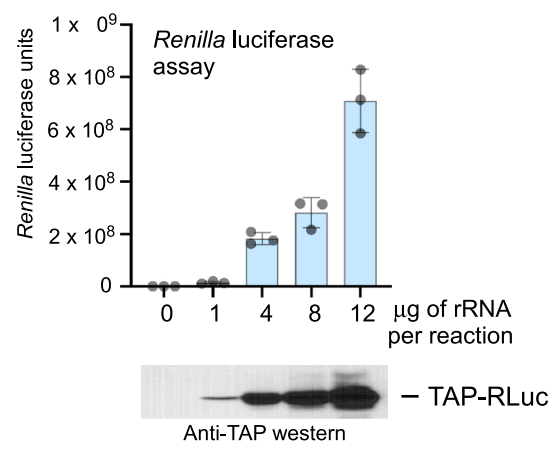

D

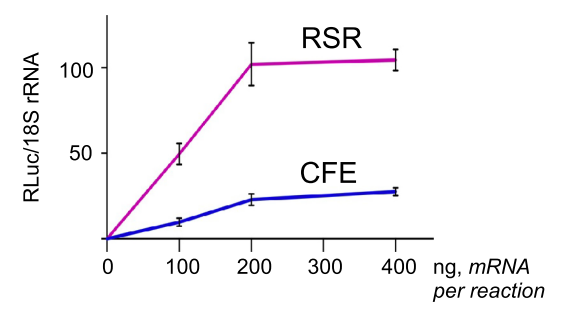

C
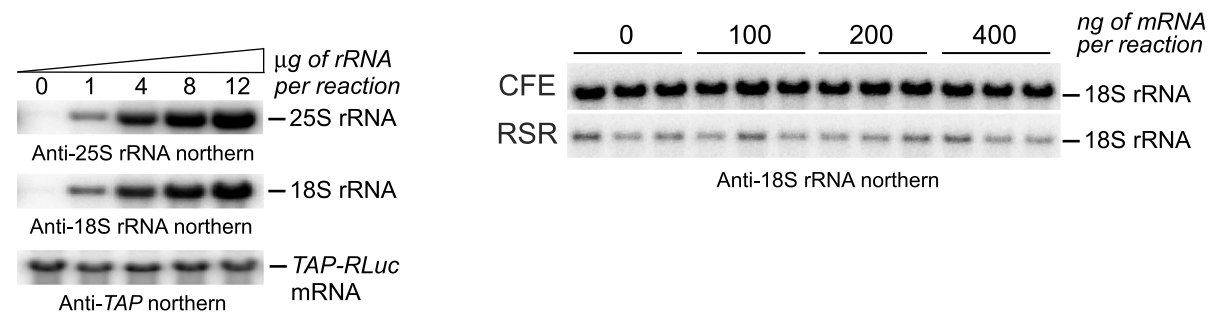

FIGURE 4. Optimization of the translation reaction. (A) Time course of translation reactions assembled with complete CFE (blue) or with ribosomes purified from CFE via 180K-centrifugation (RSR, magenta). Both reactions were programmed with 400 ng of capped TAP-Renilla mRNA reporter; the final reaction volume was $30 \mu \mathrm{L}$. Each CFE reaction was estimated to contain $60 \mu \mathrm{g}$ of the total RNA. To the RSR reactions, we added $24 \mu \mathrm{g}$ of purified ribosomes. Reaction aliquots $(4.5 \mu \mathrm{L})$ were collected at the indicated time points, levels of generated reporter proteins were measured by the Renilla luciferase assay, normalized by the 18S rRNA hybridization signal in each sample, and plotted as linear and log 10 graphs. Each reaction was set in triplicate. The bottom panel shows a representative northern blot of the RNA extracted from the reactions and hybridized with an 18S rRNA-specific probe. $(B, C)$ Efficiency of translation in RSR assay reactions depends on the concentration of purified ribosomes. (B) Indicated amounts of solubilized ribosomes derived from P180 generated by one-step centrifugation of CFE were added to S180. Each reaction was charged with $200 \mathrm{ng}$ of capped TAP-RLuc mRNA reporter. (C) Total RNA was extracted from the RSR/luciferase reactions from B and analyzed by northern hybridizations using probes specific to $25 \mathrm{~S}$ rRNA, 18S rRNA, and TAP-RLucmRNA. (D) mRNA dose dependence. Translation reactions were assembled with complete CFE (blue) or with ribosomes purified from CFE via 180K-centrifugation (RSR, magenta). Reactions were programmed with the indicated amounts of capped TAP-Renilla mRNA reporter; the final reaction volume was $15 \mu \mathrm{L}$. For the CFE reaction, we used unfractionated CFE ( $30 \mu \mathrm{g}$ total RNA), while the RSR reaction contained $4 \mu \mathrm{g}$ of purified ribosomes. RNA was extracted from the RSR/luciferase reactions and analyzed by northern hybridization with an $18 \mathrm{~S}$ rRNA-specific probe (bottom). Radioactive signal corresponding to the fulllength 18S rRNA was converted to phosphorimaging units and used to quantify the luminescent signal derived from the same sample. All reactions in $B$ and $C$ were assembled in triplicate and carried out for $90 \mathrm{~min}$ at $21^{\circ} \mathrm{C}$. In all graphs, error bars represent standard error of the mean (SEM) of three experiments.

$90 \mathrm{~min}$, followed by a Renilla luciferase assay and western blotting to assess the production of TAP-RLuc. As expected, and consistent with the previous experiment (Fig. 2A), neither luminescent signal nor TAP-RLuc protein were detected in the reaction containing S180 only (Fig. 4B, $0 \mu$ g of rRNA), suggesting that $\mathrm{S} 180$ lacks endogenous ribosomes after the 180K-centrifugation procedure. The reporter synthesis efficiency increased with increasing ribosomal content, and 
the highest amounts of TAP-RLuc were detected in the reaction containing the highest concentration of ribosomes that could be added to the $15-\mu \mathrm{L}$ reaction volume $(12 \mu \mathrm{g}$ of rRNA; Fig. 4B). Northern hybridization of RNA extracted from these RSR reactions confirmed increases of $18 \mathrm{~S}$ and $25 \mathrm{~S}$ rRNAs (Fig. 4C, top) and verified the stability of TAP-RLuc mRNA post reaction (Fig. 4C, bottom). Thus, to achieve detectable levels of the TAP-RLuc reporter, the amount of ribosomes purified by one-step centrifugation can range between $2-12 \mu \mathrm{g}$ per $15 \mu \mathrm{L}$ reaction.

\section{Optimization of the mRNA concentration}

To examine how mRNA amount affects protein synthesis in a translation reaction, we added different amounts of capped TAP-RLuc mRNA $(100,200$, and $400 \mathrm{ng})$ to $15-\mu \mathrm{L}$ translation reactions assembled with $\mathrm{S} 180$ and $4 \mu \mathrm{g}$ of P180-derived ribosomes. For comparison, we also tested different concentrations of the TAP-RLuc mRNA in reactions with unfractionated CFE. The amounts of the synthesized TAP-RLuc protein were determined by a Renilla luciferase assay, after which RNA from the luciferase reactions was extracted and analyzed by northern hybridizations as described above. This mRNA-titration experiment (Fig. 4D) demonstrated that under the conditions tested ( $4 \mu \mathrm{g}$ of ribosomes, 90 min reaction duration, $15 \mu \mathrm{L}$ reaction volume, $21^{\circ} \mathrm{C}$ ), exceeding $200 \mathrm{ng}$ of mRNA resulted in a saturation of both RSR- and CFE-based reactions. Consistent with the timecourse experiment (Fig. 4A), translation reactions performed in the RSR format were more efficient than those with unfractionated CFE (Fig. 4D).

Taken together, these data indicate that to accurately compare ribosome activity when using the RSR format of cell-free translation, concentrations of multiple components in the translation reactions must be carefully controlled. The values obtained above, including reaction time (Fig. 4A; Supplemental Fig. S2), amounts of ribosomes (Fig. 4B,C), and mRNA (Fig. 4D; Supplemental Fig. S3), provide starting points of optimization, which should be carried out in other experiments in accordance with the desired experimental goals.

\section{Translational activity of P180-derived ribosomes after centrifugation of CFE through $\mathbf{2 0 \%}$ glycerol cushion}

Purifying ribosomes via centrifugation through a cushion is routinely used in various biochemical applications (Jenner et al. 2012; Mehta et al. 2012; Khatter et al. 2014). In fact, like IP, this approach allows separation of ribosomes from low molecular weight molecules, including endogenous and exogenous cellular components, which might interfere with the translation reaction. For example, treating CFE with ribosome-modifying compounds (discussed below) would require removing the drug prior to adding ribo- somes to the translation reaction. Thus, the ability to use cushion-centrifuged ribosomes would be a powerful feature of the RSR translation system.

To assess the activity of ribosomes prepared by centrifugation through a cushion, we either directly pelleted ribosomes from CFE as described above or centrifuged CFE through a $20 \%$ glycerol cushion at $180,000 \mathrm{~g}$ for $2 \mathrm{~h}$. The resulting P180 pellets were solubilized, and $9 \mu \mathrm{g}$ of P180 were added to the ribosome-free translational lysate (S180) along with 400 ng of capped TAP-RLuc mRNA reporter. Renilla luciferase assay revealed that ribosomes isolated by centrifugation through the cushion were as active as those pelleted directly from CFE (Fig. 5A, bars 3 and 4).

\section{Activity of ribosomes purified from yeast cells by glass-bead lysis}

To establish, validate, and optimize the RSR format of cellfree translation reactions, we used the translationally active CFE as the ribosome source in the experiments above (Figs. 3-5A). The next question we wanted to address was whether ribosomes extracted directly from cells in culture would be active in the RSR format (Fig. 1B). Total cellular lysates prepared by a conventional glass bead-
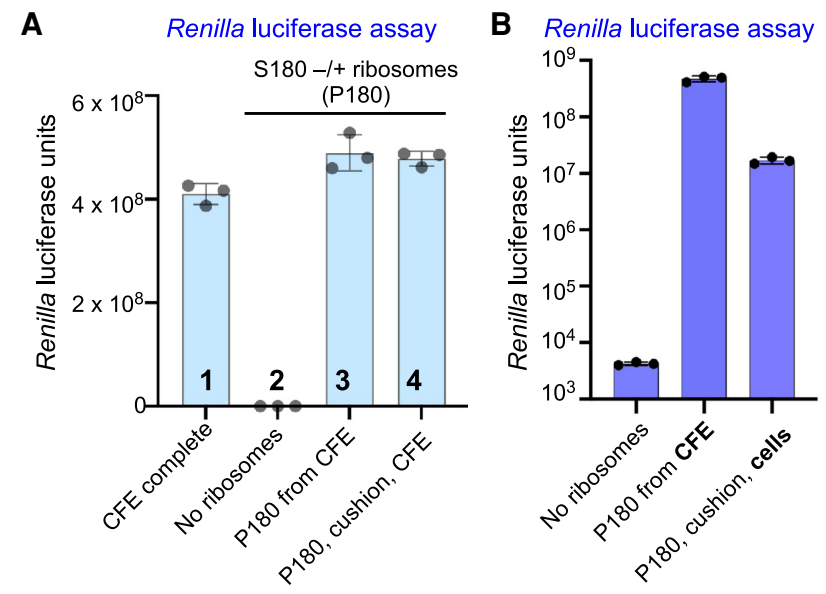

FIGURE 5. (A) Centrifugation of ribosomes through glycerol cushion does not affect their translational activity. Translation reactions were assembled with complete CFE (lane 1) or with $9 \mu \mathrm{g}$ of purified ribosomes in the RSR format (lanes 3-4). For RSR, ribosomes were pelleted directly from CFE (lane 3) or by centrifugation of CFE through a $20 \%$ glycerol cushion (lane 4). In lane 2, no ribosomes were added to the reaction. (B) Activity of ribosomes prepared from CFE and from cells lysed by glass-bead beating. RSR translation reactions were assembled with $9 \mu \mathrm{g}$ of ribosomes pelleted from the complete CFE (P180 from CFE) or with $9 \mu \mathrm{g}$ of ribosomes purified from cell lysate by $180 \mathrm{~K}$-centrifugation through $20 \%$ glycerol cushion (P180, cushion, cells). In the control reaction, no ribosomes were added, and the background levels of luminescence are detected. In $A$ and $B$, each reaction contained $400 \mathrm{ng}$ of capped TAP-RLuc mRNA reporter. Reactions were incubated at $21^{\circ} \mathrm{C}$ for $90 \mathrm{~min}$ and the reaction products were analyzed by a Renilla luciferase assay. Error bars represent SEM of three experiments. 
beating lysis technique were centrifuged through a $20 \%$ glycerol cushion at $180,000 \mathrm{~g}$ for $2 \mathrm{~h}$ at $4^{\circ} \mathrm{C}$ to separate heavy ribosomal particles from low molecular weight cellular contaminants (Fig. 1g-h). Similar to CFE-derived ribosomes, ribosomes isolated by this method showed little apparent degradation (Fig. 2A, lane 4) and were detected in the $80 \mathrm{~S}$ fraction of the sucrose gradient (Fig. 2C). When these ribosomes, freshly isolated from cells (Fig. 1g-i), were added to translation reactions containing S180 and charged with TAP-RLuc mRNA (Fig. 1-j), they demonstrated translational competency, as a measurable luminescent signal was achieved (Fig. 5B, bar 3). However, we observed a significant decline ( $\sim 30$-fold) in the reporter synthesis efficiency with cell-derived ribosomes compared to those isolated from CFE (Fig. 5B). Nevertheless, the Renilla luciferase signal was still sufficiently high, suggesting that using cell-derived ribosomes is a reasonable alternative to CFEpurified ribosomes.

\section{Practical applications of the RSR system}

The RSR system established here (Figs. 1-5) can be used for various applications. For example, the RSR approach allows the analysis of changes in translation caused by ribosomedirected effects of stressors like oxidants or chemotherapeutic drugs capable of modifying and damaging various ribosome components. To illustrate RSR's utility in assessing activity of modified ribosomes, we tested two RNA modifiers: (i) the cell-permeable drug menadione (vitamin $\mathrm{K} 3$ ), which promotes oxidation of RNA and proteins in cells (Shedlovskiy et al. 2017b; Zinskie et al. 2018; Smethurst et al. 2020); and (ii) the cell-impermeable drug cisplatin, also known to modify nucleic acids, including rRNAs (Dedduwa-Mudalige and Chow 2015; Melnikov et al. 2016). Accordingly, we isolated ribosomes from drug-treated living cells (for menadione) or treated ribosomes in vitro (for cisplatin), followed by assaying ribosome activity in cellfree translation reactions.

\section{Ribosome isolation from cells treated with menadione}

Menadione is a pro-oxidant used as an extracellular stressor of yeast cells because of its stability in the medium during yeast culture treatment and high cell wall/membrane permeability (Jamieson 1992). Previous studies have found that treating yeast cultures with high doses of menadione (up to $600 \mu \mathrm{M}$ ) triggers extensive rRNA fragmentation followed by induction of the apoptotic program (Mroczek and Kufel 2008; Shedlovskiy et al. 2017b). In contrast, treating yeast cultures with low doses of menadione (25-50 $\mu \mathrm{M})$ does not affect cell viability and is accompanied by $25 \mathrm{~S}$ rRNA cleavage specific for the expansion segment ES7L (Shedlovskiy et al. 2017b). Menadione promotes oxidation indirectly by affecting the primary cellular antioxidant gluta- thione, resulting in ROS accumulation (Ochi 1996; Kim et al. 2014; Morris et al. 2014). Because menadione-induced ribosome oxidation can occur only in the cellular context, we applied the strategy illustrated in Figure 1B to study how the activity of ribosomes is altered by a menadione treatment of the cell culture. Exponentially growing yeast cultures (BY4741 wild-type yeast strain) were treated with $50 \mu \mathrm{M}$ and $100 \mu \mathrm{M}$ menadione for $2 \mathrm{~h}$ at $30^{\circ} \mathrm{C}$ or remained untreated. Cells were lysed by glass bead shearing, and lysates were centrifuged through a $20 \%$ glycerol cushion to pellet ribosomes (Fig. 1g,h). Ribosomal pellets were resuspended in buffer $\mathrm{A}$ by shaking at $21^{\circ} \mathrm{C}$ for $30 \mathrm{~min}$ (Figs. 1-i, 3), and an aliquot of the ribosome suspension containing $2 \mu \mathrm{g}$ of RNA was analyzed by northern hybridizations with $18 \mathrm{~S}$ and $25 \mathrm{~S}$ rRNA-specific probes (Fig. 6A). Consistent with our previous studies (Shedlovskiy et al. 2017b), we detected the formation of degradation products predominantly in $25 \mathrm{~S}$ rRNA, while 18S rRNA remained less affected by the drug treatment. Therefore, we used the $18 \mathrm{~S}$ rRNA signal as a normalizer for the following experiments (Fig. 6B,C).

\section{In vitro $\left[{ }^{35} \mathrm{~S}\right]-\mathrm{Met} / \mathrm{Cys}$ incorporation into nascent polypeptides as a readout of translation}

To determine how menadione exposure affects ribosome activity in translation, P180 ribosome pellets obtained from cells treated with menadione and untreated control cells (Fig. 1B) were resuspended as described above and equal ribosome amounts, each containing $9 \mu \mathrm{g}$ of RNA (Figs. 1-j, 6A), were added to the ribosome-free (S180) CFE fraction (Fig. 1-b). This fraction was generated from CFE that derived from untreated cells and contained endogenous cellular mRNAs. The translation reactions $(15 \mu \mathrm{L})$, set in triplicate, were also supplied with an energy mix and amino acids with radioactively labeled methionine (Met) and cysteine (Cys). Aliquots of the reaction products $(4 \mu \mathrm{L})$ were collected at $10 \mathrm{~min}, 30 \mathrm{~min}$, and $60 \mathrm{~min}$ postreaction, and proteins were precipitated with TCA. The amounts of labeled nascent polypeptides (trapped on filters) generated from endogenous mRNAs present in the CFE-derived S180 were measured by scintillation counting. The obtained CPM (count per minute) values were normalized by the $18 \mathrm{~S}$ rRNA hybridization signal quantified by phosphorimaging in an aliquot of each reaction's ribosome input (Fig. 6A, bottom panel).

As expected, amounts of $\left[{ }^{35} \mathrm{~S}\right]-M e t / C y s-l a b e l e d ~ p o l y-$ peptides increased over time when ribosomes isolated from untreated cells were used (Fig. 6B, red curve). Ribosomes extracted from cells treated with $50 \mu \mathrm{M}$ menadione were also translationally active, generating $\sim 1.5$ times less total protein over time than untreated ribosomes, while ribosomes isolated from cells treated with $100 \mu \mathrm{M}$ menadione were inactive (Fig. 6B, blue and green curves). These data are consistent with our previous observation that $100 \mu \mathrm{M}$ menadione treatment promotes rRNA 
A

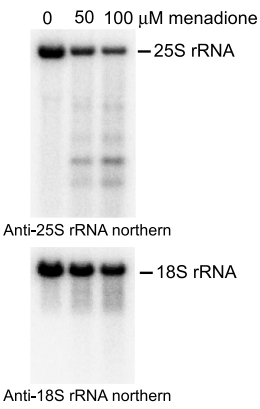

D
B

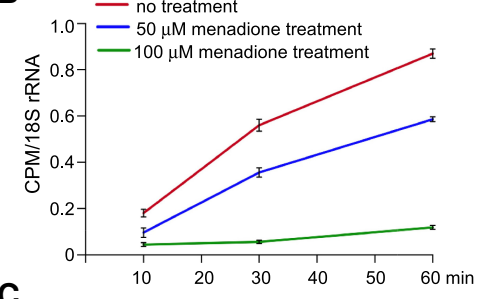

C

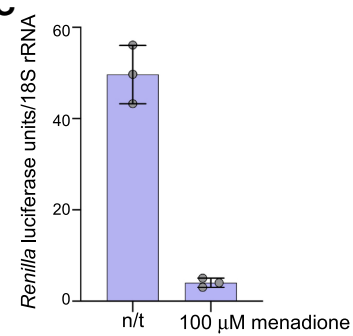

Dual luciferase reporter \begin{tabular}{l|l|} 
Firefly (ORF1) & Nano (ORF2) \\
\hline
\end{tabular}

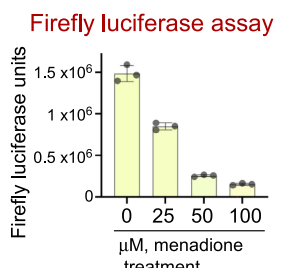

treatment

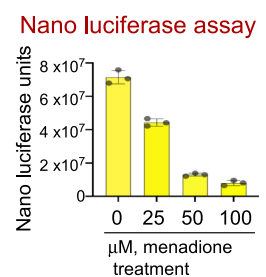

treatment
Nano Luc/FLuc ratio

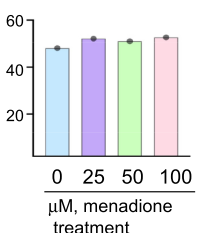

E

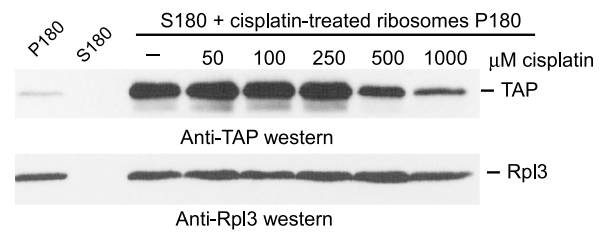

FIGURE 6. Ribosome translational activity decreases upon treatment with menadione or cisplatin in dose-dependent manner. (A) Mid-log wild-type cells BY4741 grown in YPD were treated with $50 \mu \mathrm{M}$ or $100 \mu \mathrm{M}$ menadione for $2 \mathrm{~h}$ at $30^{\circ} \mathrm{C}$ or left untreated. Cells were lysed, and ribosomes were precipitated by ultracentrifugation through $20 \%$ glycerol cushion as illustrated in Figure 1B. Ribosomal pellet P180 was resuspended in buffer $A$, and $2 \mu \mathrm{g}$ of total RNA was analyzed by northern hybridizations with the indicated probes. (B) Ribosomes ( $9 \mu \mathrm{g}$ RNA) prepared as described in A were added to translationally active ribosome-free lysate S180 prepared from CFE (Fig. 1A), along with amino acids containing labeled $\left[{ }^{35} \mathrm{~S}\right]-\mathrm{Met} / \mathrm{Cys}$. Reactions were incubated at $21^{\circ} \mathrm{C}, 4 \mu \mathrm{L}$ aliquots were taken at indicated time points, and proteins were precipitated by TCA. Incorporation of $\left[{ }^{35} \mathrm{~S}\right]-\mathrm{Met} / \mathrm{Cys}$ into nascent peptides was measured by scintillation counting; CPM (count per minute) values were plotted as graphs. $(C)$ Ribosomes (9 $\mu \mathrm{g}$ RNA) prepared as described in A were added to translation reactions containing S180 and 400 ng of capped-mRNA reporter encoding TAP-RLuc ( 56 kDa). Reaction products were analyzed by the Renilla luciferase assay. The luminescent signals were normalized by phosphorimaging units from $A$ and the resulting RLuc/18S rRNA ratios are presented as bar graphs. ( $D$, top) Schematics for Firefly-nano luciferase reporter ( $81 \mathrm{kDa})$. (Bottom) Mid-log wild-type cells BY4741 grown in YPD were treated with $0,25 \mu \mathrm{M}, 50 \mu \mathrm{M}$, or $100 \mu \mathrm{M}$ menadione for $2 \mathrm{~h}$. Ribosomes were extracted, solubilized, and added ( $9 \mu \mathrm{g}$ RNA) to translation reactions containing $400 \mathrm{ng}$ of the capped dual firefly-nano luciferase reporter mRNA. Reaction products were analyzed by Nano-Glo Dual-Luciferase Reporter assay; the Nano-Luc/FLuc ratio is shown on the right panel. (E) Complete CFE was treated with cisplatin at the concentrations indicated in the figure. Ribosomes were purified from the drug-treated CFE by centrifugation through a glycerol cushion as described for Figure 5A. Ribosomes from the resuspended P180 $(9 \mu \mathrm{g}$ RNA) were added to untreated S1 80 charged with $300 \mathrm{ng}$ of capped TAP mRNA reporter. Control reactions on the left contained ribosomes only (P180) or ribosome-free supernatant only (S180). TAP and ribosomal protein Rpl3 (control for ribosome amount) were detected by western blotting. In panels $C-E$, all translation reactions were incubated at $21^{\circ} \mathrm{C}$ for 90 min. In all graphs, error bars represent standard error of the mean (SEM) of three experiments.

fragmentation and significantly affects cell viability (Shedlovskiy et al. 2017b).

\section{Using translation reporters as a readout of translation}

As an alternative to $\left[{ }^{35} \mathrm{~S}\right]-\mathrm{Met} / \mathrm{Cys}$ labeling of polypeptides translated from endogenous mRNA present in the $\mathrm{CFE}$, translation reactions can be charged with mRNA for a reporter protein. To test this approach, we first supplied $400 \mathrm{ng}$ of capped TAP-RLuC mRNA and $9 \mu \mathrm{g}$ of ribosomes extracted from $100 \mu \mathrm{M}$ menadione-treated or untreated cells (Fig. 6A) into the translation reactions (Fig. 1-j) and measured luminescence produced by the synthesized TAP-RLuc using the Renilla luciferase assay. As in $\left[{ }^{35} \mathrm{~S}\right]$ Met/Cys-labeling, we normalized the luminescence signal by the amount of ribosomes (Fig. 6A) added to the reactions, thus generating the Rluc/18S rRNA ratios (Fig. 6C). Consistent with previous data (Fig. 6B), the amount of the protein reporter synthesized in the reactions driven by menadionetreated ribosomes was significantly lower than that of ribosomes extracted from untreated cells (Fig. 6C).

To further evaluate the processivity of ribosomes prepared from menadione-treated cells, we next tested translation of a dual firefly-nanoluciferase mRNA. Dual reporters are commonly used in translation analysis, as they represent a powerful experimental tool that allows data normalization by calculating the ratio of the ORF2 reporter over the ORF1 reporter (schematics in Fig. 6D), which helps in data interpretation and reduces experimental variability. We charged the ribosome-free translationally active lysate (S180, Fig. 1-b) with 400 ng of capped firefly-nanoluciferase (FLuc-nanoLuc, hereafter) mRNAreporter along with $9 \mu \mathrm{g}$ of ribosomes extracted from cells treated with 25 $\mu \mathrm{M}, 50 \mu \mathrm{M}$, and $100 \mu \mathrm{M}$ menadione. As a control, we used ribosomes extracted from untreated cells. Reaction products were analyzed by the 
Dual-Luciferase Reporter assay from Promega. We measured the luminescent signal derived from firefly luciferase (Fig. 6D, left panel), then measured nano-luciferase luminescence (Fig. 6D, middle panel). Synthesis of both reporters correlated negatively with increasing menadione concentrations during treatment (Fig. 6D, left and middle panels). Interestingly, the ratio of nanoLuc to FLuc remained constant in every reaction (Fig. 6D, right panel), indicating that ribosomes that remain capable of engaging in translation in menadione-treated cells can fully synthesize the entire FLuc-nanoLuc reporter and thus are not significantly impaired in their ability to carry out elongation.

\section{Reduced translational efficiency of ribosomes from CFE with high-dose cisplatin}

Cisplatin is a chemotherapeutic drug widely used to treat many types of cancer (Dasari and Tchounwou 2014). Although the main target of cisplatin is DNA, it can also modify RNA, in particular rRNAs (Mezencev 2015).

Here, we examined the effects of cisplatin on the translational ability of ribosomes in the RSR system. Since cisplatin is membrane-impermeable, we treated CFE (instead of cells, as for menadione) with various concentrations of this drug for $2 \mathrm{~h}$ at $21^{\circ} \mathrm{C}$. Untreated CFE was used as a control. To separate cisplatin-modified ribosomes from other CFE components and excess drug, ribosomes were precipitated by one-step centrifugation through $20 \%$ glycerol cushion. Ribosome-enriched pellets were washed and resuspended in $100 \mu \mathrm{L}$ of buffer A with shaking at $21^{\circ} \mathrm{C}$ for $30 \mathrm{~min}$; the $9 \mu \mathrm{g}$ of rRNA were placed into cisplatin-untreated ribosome-free lysate S180 (Fig 1A-C). The reactions were charged with $300 \mathrm{ng}$ of capped TAP mRNA reporter. Reactions were incubated at $21^{\circ} \mathrm{C}$ for 90 min (Fig. 1f) and reporter protein synthesis was analyzed by western blotting using anti-TAP antibodies, with antibodies that detect Rpl3 used as an internal control. As expected, no protein signal was detected in reactions containing only ribosomes or only S180 (Fig. 6E, lanes 1-2), while addition of ribosomes to $S 180$ resulted in strong TAP-reporter synthesis (Fig. 6E, lane 3). The ribosome translational ability declined only when cisplatin was used at high concentrations $(0.5$ and $1 \mathrm{mM}$, Fig. 5E, lanes 7-8), while treatment with 50,100 , and $250 \mu \mathrm{M}$ had no discernible effect on the reporter levels (Fig. 6E, lanes 4-6).

Previous studies have identified rRNA sites susceptible to cisplatin modifications. For example, Melnikov et al. (2016) revealed $2.6 \AA$ A-resolution crystal structures of bacterial 705 exposed to cisplatin, which demonstrated the drug's ability to stably intercalate into rRNA structures. Similarly, Rijal and Chow used in vitro and in vivo experimental systems to show that cisplatin can bind both purified $30 \mathrm{~S}$ subunits and those that are in the $70 \mathrm{~S}$ ribosomal complex (Rijal and Chow 2009). Furthermore, in yeast, cisplatin binds to RNA more efficiently than to DNA
(Hostetter et al. 2012). Taken together, our data demonstrating reduced ribosomal activity upon exposure to cisplatin, which, along with the growing evidence that cisplatin binds RNA, helps explain mechanisms of cisplatin toxicity in cells.

\section{DISCUSSION}

We have devised a yeast-based biochemical approach (outlined in Fig. 1) that allows the efficient isolation of modified or damaged ribosomes from cells or cell-free extracts. These ribosomes can be subsequently combined with undamaged, translationally active ribosome-free cell lysates, charged with an mRNA reporter or with radioactively labeled amino acids, after which the generated proteins are analyzed. The data presented in this report illustrate applications of this "Ribosome Separation and Reconstitution" (RSR) approach for studying the effects of damage to yeast ribosomes introduced both in vivo and in vitro.

Through optimizations of the RSR procedure, we established conditions under which yeast ribosomes purified from CFE or cell cultures by one-step centrifugation remain stable (Fig. 2) and retain their translational activity (Figs. 3-6). As such, translation reactions reconstituted in vitro with ribosome-free lysates and pellet-derived ribosomes result in efficient translation of both endogenous CFE-derived transcripts (Fig. 6B) and various mRNA reporters (Figs. 3-6). In previous studies, cell-free reactions reconstituted from eukaryotic ribosomes and nonribosomal translation components obtained from different sources relied on the rabbit reticulocyte lysate to generate ribosome-free supernatants containing factors necessary for translation, with cultured cells (Panthu et al. 2015; Penzo et al. 2016) or tissues and organs (Panthu et al. 2015) serving as ribosome donors. The mammalian protocols used overall similar conditions to ours to pellet ribosomes, namely, centrifugation at $140,000 \mathrm{~g}$ for $5 \mathrm{~h}$ (Penzo et al. 2016) or at $240,000 \mathrm{~g}$ for $2 \mathrm{~h} 15 \mathrm{~min}$ (Panthu et al. 2015). A significantly higher speed for ultracentrifugation of rabbit reticulocytes has been reported in (Rau et al. 1998), wherein ultracentrifugation at $420,000 \mathrm{~g}$ for $20 \mathrm{~min}$ was sufficient to separate cytosolic components from ribosomes and ribosome-associated proteins. Examining rRNAs and r-protein Rpl3 as a readout of ribosomal content in the $\mathrm{S} 180$ supernatant generated by centrifuging yeast CFE at $180,000 \mathrm{~g}$ for $2 \mathrm{~h}$ indicates that these conditions are sufficient to generate yeast lysate devoid of ribosomes (Figs. 2A, 4C, 6E), while tRNAs remain largely in the S180 supernatant after the 180K-centrifugation (Fig. 2A). Functional assays further support these data, as no protein reporter products were detected in translation reactions that lacked exogenously added ribosomes (Figs. 4B, 5A, B, 6E). 
Our experiments highlight several critical parameters for a comparative analysis of different ribosome preparations with the RSR approach. First, we find that ribosome pellets should be resuspended under conditions that produce a homogeneous ribosome suspension; the solubilization temperature of the ribosome-enriched P180 (Fig. 1b) should not exceed $21^{\circ} \mathrm{C}$ for BY4741-derived ribosomes (but may need to be optimized for other yeast strains). Second, the amounts of ribosomes added to the translation reactions must be carefully controlled. While the RSR format of cell-free translation reactions tolerates different ratios of ribosomes to the ribosome-free fraction (Fig. $4 B)$, it is important to maintain the same ratio in all reactions in a given set. One useful approach to control the amount of ribosomes added to a reaction is through northern blotting-based quantification of 18S rRNA (Figs. 4, 6; Supplemental Figs. S2, S3). Third, the mRNA concentration and reaction time sufficient to obtain detectable amounts of the translated product while still within the acceptable synthesis range (Fig. 4A,D; Supplemental Figs. S2, S3) may vary for individual mRNA reporters and need to be optimized. Thus, it is important to perform the mRNA titration and time kinetics experiments to determine the optimal range of these parameters for each new batch of reagents.

Interestingly, cell-free protein translation using ribosomes isolated through the RSR protocol was consistently observed to be more efficient in our hands than unfractionated CFE (Fig. 4A; Supplemental Fig. S2B, upper panels). The reasons for this unexpected observation are currently unclear and will require additional experimentation to explain. Compared to ribosomes purified by pelleting from CFE (directly or through glycerol cushion), those extracted from cells via conventional glass bead-beating procedure were approximately an order of magnitude less efficient in the translation reaction (Fig. 5B). Thus, the cryogenic lysis technique used in our CFE preparation (Trainor et al. $2021 \mathrm{~b}$ ) appears to be the preferable way for maintaining the ribosomes' translational activity during their isolation. The main disadvantage of this method is that it requires a large sample volume, is relatively laborious, and limited by the number of samples that can be processed simultaneously. Further optimizing buffer composition for beadbeating lysis could be a reasonable strategy to improve the recovery of active ribosomes from cells. Another currently untested possibility is to apply a spheroplastingbased cell lysis approach, which requires enzymatic digestion of the cell wall followed by lysis using osmotic pressure, freeze-thawing, or other cell-disruption strategies (Darling et al. 1969; Mann et al. 1972; Izawa and Unger 2017).

In this study, we tested RSR with ribosomes subjected to menadione-induced oxidative stress in the intracellular environment and to an in vitro treatment with the chemotherapeutic drug cisplatin. The results presented in Figure 6 demonstrate that both conditions affected the ribosomes' total translational activity in a dose-dependent manner. How ribosome modifications affect translation of challenging sequences, such as mRNA with stalls, rare codon stretches, or programmed ribosome frameshifting, can be addressed in future studies using the RSR methodology in combination with dual-luciferase reporters (Fig. 6D).

In conclusion, the RSR protocol described here provides an effective way to assess translational competency of the chemically modified or damaged ribosomes without the confounding damage to other translation factors. Data from our laboratory demonstrate that this approach can also be adapted to studying translation properties of genetically altered ribosomes, such as those that contain mutations in r-proteins (B.M.T. and N.S, personal observations). Thus, we anticipate that RSR will be broadly applicable for dissecting translational consequences of diverse types of modifications in ribosome composition and structure.

\section{MATERIALS AND METHODS}

\section{Yeast strain, medium, yeast culture treatment}

We used YPD media (1\% yeast extract, 2\% peptone, and 2\% dextrose) that was sterilized by filtration through a $0.2 \mu \mathrm{m}$ PES membrane filter system ("Rapid-Flow" from Thermo Scientific). Wild-type BY4741 (MATa his3-1 leu2- 0 met15- 0 ura3-0) was purchased from Open Biosystems. For experiments with menadione treatment, overnight BY4741 yeast cultures were diluted with fresh YPD at $A_{600}$ of $\sim 0.3$ and grown for an additional $2-4 \mathrm{~h}$ at $30^{\circ} \mathrm{C}$ to $A_{600}$ of $\sim 0.6-0.7$. Various concentrations of menadione (indicated in figures and figure legends) were added to the cultures; cells were grown for an additional $2 \mathrm{~h}$ at $30^{\circ} \mathrm{C}$ agitating, harvested, washed with water, and lysed.

\section{Antibodies, chemicals, and enzymes}

The following antibodies were used: Peroxidase anti-peroxidase complex (PAP) (Sigma, cat\# P1291) to detect TAP; anti-Rpl3 (ScRPL3, Developmental Studies Hybridoma Bank, University of lowa); anti-mouse IgG-HRP (GE-Healthcare, cat\# NA931).

Cisplatin was purchased from Sigma (cat\# PHR1624), menadione from Enzo (cat\# ALX-460-007-G010), DTT from Sigma (cat\# D0632), SYBR Gold from Thermo Fisher Scientific (cat\# S11494); TRI-REAGENT-LS was from Molecular Research Center Inc (cat\# TS 120); formamide was purchased from Sigma (cat\# 47670$25 \mathrm{ML}-\mathrm{F}$ ) and stored in $1 \mathrm{~mL}$ aliquots at $-80^{\circ} \mathrm{C}$. EasyTag EXPRESS ${ }^{35} \mathrm{~S}$ Protein Labeling mix, $\left[{ }^{35} \mathrm{~S}\right], 11 \mathrm{mCi} / \mathrm{mL}$, was obtained from PerkinElmer (cat\# NEG772002MC).

RiboLock (cat\# EO0381), DreamTaq PCR 2x master mix (cat\# K1071), 100 mM ATP solution (cat\# R0441), 100 mM GTP solution (cat\# R0461), proteinase K (cat\# EO0491), and all the restriction enzymes were obtained from Thermo Fisher Scientific. Creatine phosphokinase was purchased from BioVision, creatine phosphate from WWR (cat\# 97061-328). A total of $1 \mathrm{mM}$ solution of 20 essential amino acids, complete and minus Methionine and 
Cysteine, were from Promega (cat\# L4461 and L5511, respectively); Ambion mMESSAGE mMACHINE T7 Transcription kit was purchased from Thermo Fisher Scientific (cat\# AM1344); Crescendo chemiluminescent HRP detection reagent was from Millipore Sigma (cat\# WBLUR0100); DNA Clean and Concentrator kit was from Zymo Research (cat\# D4004); PD-10 columns Sephadex G-25 $(20 \times 80 \mathrm{~mm})$ were from GE Healthcare (cat\# 17085101).

\section{Plasmids}

pYes2 was purchased from Invitrogen. To generate pYes-TAP, we amplified the TAP sequence using the pBS1761 plasmid (a kind gift of Dr. Mike Henry) as a template with the forward primer containing the BamHI site and the reverse primer containing a stop codon followed by the Xhol site; PCR TAP-product was cloned into pYes between BamHI and Xhol. The same template and the forward primer were used to amplify a no-stop TAP coding sequence, in which the reverse primer annealed upstream of the stop codon and contained the Xhol site. TAPNoStop PCR product was cloned into pYes between $\mathrm{BamHI}$ and $\mathrm{Xhol}$, resulting in the pYes-TAPNoStop construct. The Renilla luciferase gene was amplified by PCR from pJD375 with a forward primer containing the Xhol site and reversed primer containing the Xbal site and cloned into pYes-TAPNoStop between the Xhol and Xbal sites, resulting in the pYes-TAP-RLuc fusion. The sequences of pYesTAP and PYes-TAP-RLuc were verified by sequencing.

To generate the dual-luciferase reporter construct pYes-FLucnanoLuc, a firefly luciferase gene was amplified using pJD375 plasmid as a template (a kind gift of Dr. Jonathan Dinman), with the forward primer containing the Hindlll site and the reverse primer containing the BamHI site, whereby the reverse primer was designed to anneal upstream of the firefly luciferase gene stop codon. The PCR product was cloned into pYes2 between $\mathrm{BamHI}$ and HindIII, resulting in the pYes-FLucNoSTOP construct. Nano-luciferase was amplified using pF4Ag NanoLuc plasmid from Addgene (cat\# 137777) as a template. The forward primer contained the BamHI site, while the reverse primer contained the Xhol site. The PCR product was cloned into the pYesFLucNoSTOP construct between the BamHI and $\mathrm{Xhol}$ sites. The sequence of pYes-FLuc-nanoLuc was verified by sequencing.

\section{RNA isolation, northern blotting, and signal quantification}

To isolate RNA from CFE, S180, P180, and from in vitro translation/ Renilla luciferase reactions, we used TRI REAGENT-LS according to the manufacturer's recommendations. To isolate RNA from gradient fractions, each fraction was treated with $100 \mu \mathrm{g} / \mathrm{mL}$ proteinase $\mathrm{K}$ in the presence of $1 \%$ SDS and $10 \mathrm{mM}$ EDTA for $20 \mathrm{~min}$ at $42^{\circ} \mathrm{C}$, followed by phenol/chloroform extraction and isopropanol precipitation. All RNA pellets were resuspended in FAE solution (Formamide, $10 \mathrm{mM}$ EDTA) for $15 \mathrm{~min}$ at $65^{\circ} \mathrm{C}$, with shaking. RNA was separated on $1.2 \%$ formaldehyde-containing agarose gel as described in Mansour and Pestov (2013). Prior to transfer onto Nylon membrane (GE Healthcare, cat\# NS0921), gels were stained with SYBR Gold and scanned using a Typhoon 9200 imager (GE Healthcare) at $532 \mathrm{~nm}$ to visualize RNA. For hybridizations, we used a [ $\left.{ }^{32} \mathrm{P}\right]$-labeled probe specific for the gene encoding TAP (5'-GCCGAATTCTCCCTGAAAA-3'), a [ ${ }^{32} \mathrm{P}$-labeled probe y540 against $25 \mathrm{~S}$ rRNA (5'-TCCTACCTGATTTGAGGTCAAAC-3'), or a $\left[{ }^{32} \mathrm{P}\right]$-labeled probe y500 against $18 \mathrm{~S}$ rRNA (5'-AGAATTTCACC TCTGACAATTG-3'). We used Typhoon 9200 in the phosphorimaging mode to detect a radioactive signal, which was analyzed with ImageQuant software (GE Healthcare). For quantification, the volume of the hybridization signal corresponding to the RNA species of interest was converted to phosphorimaging units, and the background (average image background) was subtracted.

\section{CFE (cell-free extract) preparation}

The cryogenic lysis-based method for CFE preparation is described in detail in Trainor et al. (2021b). In brief, cells of the Saccharomyces cerevisiae BY4741 strain were grown in $1 \mathrm{~L}$ of YPD medium to $\mathrm{OD}_{600} \sim 0.8$, harvested by centrifugation, washed twice in $\mathrm{H}_{2} \mathrm{O}$ and twice in freshly prepared buffer $A$ [20 mM Hepes-KOH (pH 7.4), 100 mM KOAc, 2 mM Mg(OAc) $2 \mathrm{mM}$ DTT]. The weight of the cell pellet was measured, and the pellet was resuspended in buffer A containing $8 \%$ mannitol in a 2:3 volume/cell weight ratio. Cell slurry was dripped directly into liquid nitrogen to form small ice beads. Frozen yeast/buffer beads were transferred into a prechilled grinding vial containing a metal rod and placed into a SPEX freezer mill chamber filled with liquid nitrogen. Yeast/buffer beads were powdered using the following setting: 1 min of grind, 1 min off, eight cycles in total. The powdered cells were transferred into a prechilled $10.4 \mathrm{~mL}$ ultracentrifuge tube (Beckman), allowed to thaw on ice, and yeast suspension was centrifuged in a Beckman ultracentrifuge for $15 \mathrm{~min}$ at $4^{\circ} \mathrm{C}$ at $30,000 \mathrm{~g}$ using a fixed-angle Beckman rotor Type $80 \mathrm{Ti}$. The clear phase between the pellet and cloudy upper lipid layer was collected $(\sim 6 \mathrm{~mL})$ and centrifuged again for $35 \mathrm{~min}$ at $4^{\circ} \mathrm{C}$ at $100,000 \mathrm{~g}$ in a Beckman rotor Type $80 \mathrm{Ti}$. Once again, the clear phase between the pellet and cloudy upper layer was collected, and $2.5 \mathrm{~mL}$ was applied on gel filtration column PD10 Sephadex G-25 (GE Healthcare) preequilibrated in buffer A containing $20 \%$ glycerol at $4{ }^{\circ} \mathrm{C}$. For elution, also performed at $4^{\circ} \mathrm{C}$, we used $5 \mathrm{~mL}$ of buffer A containing 20\% glycerol and collected 10 fractions ( $500 \mu \mathrm{L}$ each). RNA content in each fraction was measured spectrophotometrically, and fractions with at least $60 \%-$ $75 \%$ of the highest RNA concentration were pooled, aliquoted into Eppendorf tubes $(100 \mu \mathrm{L}$ aliquots) and frozen in liquid nitrogen for storage at $-80^{\circ} \mathrm{C}$. In this procedure, we did not use protease or RNase inhibitors.

\section{PCR and RNA reporter preparation}

PCR reactions and reporter RNA synthesis were performed as described in Trainor et al. (2021b) with minor modifications. Briefly, a sequence corresponding to a reporter gene cloned in pYes2 as described in the "Plasmids" section was amplified with DreamTaq polymerase using forward (5'-CGGATCGGA CTACTAGCAGCTG-3') and reverse (5'-TTCATTAATGCAGGG CCGCAAATT-3') primers that anneal upstream and downstream from the T7 promoter and the CYC1 terminator elements on pYes2, respectively. PCR products were concentrated using ZYMO columns. m7G-capped mRNA was generated using $1 \mu \mathrm{g}$ of PCR-generated DNA template and mMESSAGE mMACHINE T7 Transcription kit, according to the manufacturer's recommendations. The reaction was carried out at $37^{\circ} \mathrm{C}$ for $2 \mathrm{~h}$, followed by 
DNase treatment for $15 \mathrm{~min}$ at $37^{\circ} \mathrm{C}$ and RNA precipitation with $\mathrm{LiCl}$. RNA pellet was washed with $80 \% \mathrm{EtOH}$, air-dried, and resuspended in $30 \mu \mathrm{L}$ of $\mathrm{H}_{2} \mathrm{O}$. Concentration was determined; RNA was aliquoted and stored at $-80^{\circ} \mathrm{C}$.

\section{Ribosome isolation for RSR}

One aliquot of CFE $(100 \mu \mathrm{L}$, RNA concentration $\sim 5.6 \mu \mathrm{g} / \mu \mathrm{L})$ was centrifuged at $180,000 \mathrm{~g}$ for $2 \mathrm{~h}$ in a Beckman TLA55 rotor $(55,000$ rpm) at $4^{\circ} \mathrm{C}$. The supernatant was collected, transferred to a new tube, and stored on ice (S180). The pellet was rinsed with buffer $A$ [20 mM Hepes- $\mathrm{KOH}$, pH 7.4; 100 mM KOAc; 2 mM Mg(OAc) ; and $2 \mathrm{mM} \mathrm{DTT}$ ] (Wu and Sachs 2014), resuspended in $100 \mu \mathrm{L}$ of the same buffer by agitation at $21^{\circ} \mathrm{C}$ for $30 \mathrm{~min}$ (or as indicated in figure legends), centrifuged using a tabletop centrifuge at $21,000 \mathrm{~g}$ for $15 \mathrm{~min}$ at $4^{\circ} \mathrm{C}$, and ribosome suspension was transferred into a new tube. RNA concentration was measured. Alternatively, we centrifuged $100 \mu \mathrm{L}$ of complete CFE through the $20 \%$ glycerol cushion $(500 \mu \mathrm{L})$ prepared in buffer $A$ at $180,000 \mathrm{~g}$ for $2 \mathrm{~h}$ in TLA55 rotor $(55,000 \mathrm{rpm})$ at $4^{\circ} \mathrm{C}$. The supernatant was carefully discarded; the ribosomal pellet was processed as described above.

To isolate ribosomes from cells, cells were collected by centrifugation using preparative centrifuge at $2200 \mathrm{~g}$ (we used an Eppendorf centrifuge 5810R equipped with the A-4-62 rotor set at $3300 \mathrm{rpm}$ for $3 \mathrm{~min}$ at $4^{\circ} \mathrm{C}$ ). Cell pellets were washed twice with buffer A supplemented with $200 \mu \mathrm{g} / \mathrm{mL}$ of heparin (used as an RNase inhibitor) and lysed by 10-12 cycles of $30 \mathrm{sec}$ vortexing followed by a 30 sec incubation on ice in the presence of 425-600 $\mu \mathrm{m}$ glass beads (Sigma, cat\# G8772). Cell lysates were cleared by centrifugations at $3200 \mathrm{~g}$ for $10 \mathrm{~min}$ and at $21,000 \mathrm{~g}$ for $15 \mathrm{~min}$ in a tabletop centrifuge at $4^{\circ} \mathrm{C}$; the supernatant was layered onto $20 \%$ glycerol cushion $(500 \mu \mathrm{L})$ prepared in buffer $\mathrm{A}$ and centrifuged at $180,000 \mathrm{~g}$ for $2 \mathrm{~h}$ in TLA55 rotor $(55,000 \mathrm{rpm})$ at $4^{\circ} \mathrm{C}$. Supernatant was discarded; the ribosomal pellet was processed as described above for CFE.

\section{Translation reactions using complete CFE}

For one reaction $(15 \mu \mathrm{L})$, we used $7.5 \mu \mathrm{L}$ of CFE, $1.5 \mu \mathrm{L}$ of RNA (200$400 \mathrm{ng})$, and $6 \mu \mathrm{L}$ of $2.5 \times$ master mix [ $50 \mathrm{mM}$ Hepes-KOH (pH 7.4), $25 \mu \mathrm{M}$ each amino acid, $5 \mathrm{mM} \mathrm{Mg}(\mathrm{OAc})_{2}, 125 \mathrm{mM} \mathrm{KOAc}$, $50 \mathrm{mM}$ creatine phosphate, $0.15 \mathrm{U}$ creatine kinase, $5 \mathrm{mM}$ DTT, $2.5 \mathrm{mM}$ ATP, $0.25 \mathrm{mM}$ GTP, $1 \cup$ RiboLock]. Reactions were incubated at $21^{\circ} \mathrm{C}$ for $30-180 \mathrm{~min}$ (indicated in figure legends).

\section{Translation reactions using RSR format}

For RSR translation reactions with mRNA reporters, we applied the protocol for translation reactions described for complete CFE (see above), with an exception that instead of $7.5 \mu \mathrm{L}$ of CFE, we used $6 \mu \mathrm{L}$ of ribosome-free supernatant (S180) and 1.5 $\mu \mathrm{L}$ of ribosomes (concentrations are indicated in figure legends and in text). Reactions were incubated at $21^{\circ} \mathrm{C}$ for $30-180 \mathrm{~min}$ (indicated in figure legends).

For RSR translation reactions with endogenous transcripts present in CFE, we used $6 \mu \mathrm{L}$ of ribosome-free supernatant (S180), $1.5 \mu \mathrm{L}$ of ribosomes (concentrations are indicated in figure leg- ends and in text), and $7.5 \mu \mathrm{L}$ of $2 \times$ master mix [ $40 \mathrm{mM}$ Hepes$\mathrm{KOH}(\mathrm{pH}$ 7.6), $20 \mu \mathrm{M}$ of essential amino acids minus Methionine and Cysteine, $4 \mathrm{mM} \mathrm{Mg}(\mathrm{OAc})_{2}, 100 \mathrm{mM} \mathrm{KOAc}$ $40 \mathrm{mM}$ creatine phosphate, $0.12 \mathrm{U}$ creatine kinase, $4 \mathrm{mM}$ DTT, $2 \mathrm{mM}$ ATP, $0.2 \mathrm{mM}$ GTP, $0.8 \mathrm{U}$ RiboLock and $1 \mathrm{mCi}$ EasyTag EXPRESS $\left[{ }^{35} \mathrm{~S}\right] \mathrm{Met} /$ Cys Protein Labeling mix]. Reactions were incubated at $21^{\circ} \mathrm{C}$. At 5,30 , and $45 \mathrm{~min}, 4 \mu \mathrm{L}$ aliquots were taken from the reaction tube and added to $96 \mu \mathrm{L}$ of $1 \mathrm{M} \mathrm{NaOH}$; tubes were incubated at $37^{\circ} \mathrm{C}$ for $10 \mathrm{~min}$ (to hydrolyze RNA), mixed with $900 \mu \mathrm{L}$ of ice-cold $25 \%$ TCA supplemented with $2 \%$ casamino acids and incubated on ice for $30 \mathrm{~min}$ to precipitate the translation products. Precipitation mixtures were applied on Whatman GF/A glass fiber filters, washed six times with 5\% TCA, once with 70\% ethanol, air-dried, and placed in a scintillation vial. A total of $2 \mathrm{~mL}$ of scintillator was added into each vial and incorporation of $\left[{ }^{35} \mathrm{~S}-\mathrm{Met} / \mathrm{Cys}\right]$ into polypeptides was determined by counting in a scintillation counter.

\section{Cisplatin treatment of ribosomes}

Aliquots of CFE were treated with various concentrations of cisplatin (as indicated in Figure $6 \mathrm{E}$ ) at $21^{\circ} \mathrm{C}$ for $2 \mathrm{~h}$. Ribosomes were next isolated for RSR as described above using centrifugation through the $20 \%$ glycerol cushion. Resuspended ribosome pellets (9 $\mu \mathrm{g}$ of RNA) were added to $15 \mu \mathrm{L}$ translation reactions containing $300 \mathrm{ng}$ of the capped TAP mRNA reporter. Reactions were incubated at $21^{\circ} \mathrm{C}$ for $90 \mathrm{~min}$ and proteins were analyzed by western blotting using PAP to detect TAP. Antibodies against Rpl3 were used to control loading.

\section{Luciferase assays and statistical analysis}

We used the Renilla Luciferase Assay System from Promega (cat\#E2810) and the Nano-Glo Dual-Luciferase Reporter Assay System (cat\#N1610) according to the manufacturer's protocol. The luminescent signal was measured on a GLOMAX 20/20 luminometer. Statistical analysis was performed by one-way ANOVA with GraphPad PRISM 9.

For RNA and protein extraction from the luciferase reaction, $100 \mu \mathrm{L}$ of TRI REAGENT-LS reagent were added to $100 \mu \mathrm{L}$ of the luciferase reaction. Samples were stored at $-80^{\circ} \mathrm{C}$ prior to processing according to the manufacturer's recommendations. RNA pellets were resuspended in $12 \mu \mathrm{L}$ of FAE (formamide, $10 \mathrm{mM}$ EDTA) (Shedlovskiy et al. 2017a), and equal volumes of the dissolved RNA $(5 \mu \mathrm{L})$ were analyzed by northern hybridizations using [ $\left.{ }^{32} \mathrm{P}\right]$-labeled probes specific for $18 \mathrm{~S}$ and $25 \mathrm{~S}$ rRNAs. The radioactive signals corresponding to the rRNAs were measured as phosphorimaging units to obtain RLuc/18S rRNA and RLuc/25S rRNA ratios, where RLuc is the Renilla luciferase luminescence units, and $18 \mathrm{~S}$ rRNA and $25 \mathrm{~S}$ rRNA represent phosphorimaging units corresponding to the full length rRNAs in the same reaction.

\section{Western blotting}

To analyze in vitro translation reaction products, proteins were isolated from $15 \mu \mathrm{L}$ of the translation reactions using TRI REAGENT-LS according to the manufacturer's recommendations. Protein pellets were analyzed as described in Trainor et al. 
(2021a). In brief, protein pellets were resuspended in $50 \mu \mathrm{L}$ of $1 \times$ SDS-PAGE loading dye, $10 \mu \mathrm{L}$ were resolved by SDS-PAGE using $10 \%$ polyacrylamide gels, transferred onto nitrocellulose membrane, and blocked with $10 \%$ milk in PBS-0.1\% Tween 20 (PBST). Membranes were incubated with PAP or anti-Rpl3 primary antibodies, washed with PBST, and for Rpl3 blots, incubated with anti-mouse secondary antibodies. For detection, we used Crescendo chemiluminescent HRP detection reagent.

\section{Sucrose gradient centrifugation analysis}

To analyze CFE, cellular lysate, CFE-derived, or cell-derived solubilized ribosomes by sucrose gradient centrifugation analysis, 150 $\mu \mathrm{g}$ of total RNA was loaded onto $15 \%-45 \%(\mathrm{w} / \mathrm{v})$ sucrose gradients prepared in $70 \mathrm{mM} \mathrm{NH}_{4} \mathrm{Cl}, 4 \mathrm{mM} \mathrm{MgCl}_{2}$, and $10 \mathrm{mM}$ Tris$\mathrm{HCl}$ (pH 7.4). The volume of each gradient was $11 \mathrm{~mL}$. Gradients were centrifuged at $188,000 \mathrm{~g}$ at $4^{\circ} \mathrm{C}$ for $4 \mathrm{~h}$ in a Beckman SW41Ti rotor (36,000 rpm) and fractionated into 12 fractions (1 $\mathrm{mL}$ each) using a Beckman fraction recovery system connected to an EM-1 UV monitor (Bio-Rad).

\section{SUPPLEMENTAL MATERIAL}

Supplemental material is available for this article.

\section{ACKNOWLEDGMENTS}

We are grateful to Anton A. Komar, Russell Sapio, and Daniel Smethurst for discussion, comments on the manuscript, and technical assistance. We thank Mike Henry for the pBS1761 plasmid and Jonathan Dinman for the pJD375 plasmid. We would like to express our gratitude to Tatyana Klimova for editing this manuscript. This study was supported by the National Institutes of Health (NIH) grant R01GM114308 (to N.S.) and by the New Jersey Health Foundation (NJHF) grant PC13-21CV (to N.S.).

Author contributions: D.G.P., N.S., and B.M.T. conceptualized the idea; N.S. and B.M.T. performed the experiments; D.G.P., N.S., and B.M.T. analyzed the data; N.S. wrote the original draft; B.M.T. and N.S. reviewed and edited the manuscript; N.S., D.G. P., and B.M.T. revised the manuscript. N.S. provided supervision and funding.

Received June 3, 2021; accepted August 18, 2021.

\section{REFERENCES}

Algire MA, Maag D, Savio P, Acker MG, Tarun SZ, Sachs AB, Asano K, Nielsen KH, Olsen DS, Phan L, et al. 2002. Development and characterization of a reconstituted yeast translation initiation system. RNA 8: 382-397. doi:10.1017/S1355838202029527

Altmann M, Sonenberg N, Trachsel H. 1989. Translation in Saccharomyces cerevisiae: initiation factor 4E-dependent cellfree system. Mol Cell Biol 9: 4467-4472. doi:10.1128/MCB.9.10 .4467

Carlson ED, Gan R, Hodgman CE, Jewett MC. 2012. Cell-free protein synthesis: applications come of age. Biotechnol Adv 30: 11851194. doi:10.1016/j.biotechadv.2011.09.016

Chan CTY, Pang YLJ, Deng W, Babu IR, Dyavaiah M, Begley TJ, Dedon PC. 2012. Reprogramming of tRNA modifications controls the oxidative stress response by codon-biased translation of proteins. Nat Commun 3: 937. doi:10.1038/ncomms1938

Chong S. 2014. Overview of cell-free protein synthesis: historic landmarks, commercial systems, and expanding applications. Curr Protoc Mol Biol 108: 16.30.1-16.30.11. doi:10.1002/ 0471142727.mb1630s108

Cox RA, Pratt H, Huvos P, Higginson B, Hirst W. 1973. A study of the thermal stability of ribosomes and biologically active subribosomal particles. Biochem J 134: 775-793. doi:10.1042/bj1340775

Danielsson J, Mu X, Lang L, Wang H, Binolfi A, Theillet F-X, Bekei B, Logan DT, Selenko P, Wennerström H, et al. 2015. Thermodynamics of protein destabilization in live cells. Proc Natl Acad Sci 112: 12402-12407. doi:10.1073/pnas.1511308112

Darling S, Theilade J, Birch-Andersen A. 1969. Kinetic and morphological observations on Saccharomyces cerevisiae during spheroplast formation. J Bacteriol 98: 797-810. doi:10.1128/jb.98.2 .797-810.1969

Dasari S, Tchounwou PB. 2014. Cisplatin in cancer therapy: molecular mechanisms of action. Eur J Pharmacol 740: 364-378. doi:10 .1016/j.ejphar.2014.07.025

Dedduwa-Mudalige G, Chow C. 2015. Cisplatin targeting of bacterial ribosomal RNA hairpins. IJMS 16: 21392-21409. doi:10.3390/ ijms160921392

Dougherty SE, Maduka AO, Inada T, Silva GM. 2020. Expanding role of ubiquitin in translational control. Int J Mol Sci 21: 1151. doi:10 .3390/ijms21031151

Endres L, Dedon PC, Begley TJ. 2015. Codon-biased translation can be regulated by wobble-base tRNA modification systems during cellular stress responses. RNA Biol 12: 603-614. doi:10.1080/ 15476286.2015.1031947

Gu C, Begley TJ, Dedon PC. 2014. tRNA modifications regulate translation during cellular stress. FEBS Lett 588: 4287-4296. doi:10 .1016/j.febslet.2014.09.038

Hostetter AA, Osborn MF, DeRose VJ. 2012. RNA-Pt adducts following cisplatin treatment of Saccharomyces cerevisiae. ACS Chem Biol 7: 218-225. doi:10.1021/cb200279p

Izawa T, Unger A-K. 2017. Isolation of mitochondria from Saccharomyces cerevisiae. Methods Mol Biol 1567: 33-42. doi:10.1007/978-1-4939-6824-4_3

Jamieson DJ. 1992. Saccharomyces cerevisiae has distinct adaptive responses to both hydrogen peroxide and menadione. $J$ Bacteriol 174: 6678-6681. doi:10.1128/jb.174.20.6678-6681 .1992

Jenner L, Melnikov S, de Loubresse N G, Ben-Shem A, Iskakova M, Urzhumtsev A, Meskauskas A, Dinman J, Yusupova G, Yusupov M. 2012. Crystal structure of the $80 \mathrm{~S}$ yeast ribosome. Curr Opin Struct Biol 22: 759-767. doi:10.1016/j.sbi.2012.07.013

Khatter H, Myasnikov AG, Mastio L, Billas IML, Birck C, Stella S, Klaholz BP. 2014. Purification, characterization and crystallization of the human $80 \mathrm{~S}$ ribosome. Nucleic Acids Res 42: e49. doi:10 .1093/nar/gkt1404

Kim G, Weiss SJ, Levine RL. 2014. Methionine oxidation and reduction in proteins. Biochim Biophys Acta 1840: 901-905. doi:10 .1016/j.bbagen.2013.04.038

Kuroha K, Zinoviev A, Hellen CUT, Pestova TV. 2018. Release of ubiquitinated and non-ubiquitinated nascent chains from stalled mammalian ribosomal complexes by ANKZF1 and Ptrh1. Mol Cell 72: 286-302.e8. doi:10.1016/j.molcel.2018.08.022

Mann JW, Heintz CE, Macmillan JD. 1972. Yeast spheroplasts formed by cell wall-degrading enzymes from Oerskovia sp. J Bacteriol 111: 821-824. doi:10.1128/jb.111.3.821-824.1972

Mansour FH, Pestov DG. 2013. Separation of long RNA by agaroseformaldehyde gel electrophoresis. Anal Biochem 441: 18-20. doi:10.1016/j.ab.2013.06.008 
Mazaré N, Oudart M, Cheung G, Boulay A-C, Cohen-Salmon M. 2020. Immunoprecipitation of ribosome-bound mRNAs from astrocytic perisynaptic processes of the mouse hippocampus. STAR Protoc 1: 100198. doi:10.1016/j.xpro.2020.100198

Mehta P, Woo P, Venkataraman K, Karzai AW. 2012. Ribosome purification approaches for studying interactions of regulatory proteins and RNAs with the ribosome. Methods Mol Biol 905: 273-289. doi:10.1007/978-1-61779-949-5_18

Melnikov SV, Söll D, Steitz TA, Polikanov YS. 2016. Insights into RNA binding by the anticancer drug cisplatin from the crystal structure of cisplatin-modified ribosome. Nucleic Acids Res 44: 4978-4987. doi:10.1093/nar/gkw246

Mezencev R. 2015. Interactions of cisplatin with non-DNA targets and their influence on anticancer activity and drug toxicity: the complex world of the platinum complex. Curr Cancer Drug Targets 14: 794-816. doi:10.2174/1568009614666141128105146

Morris G, Anderson G, Dean O, Berk M, Galecki P, Martin-Subero M, Maes M. 2014. The glutathione system: a new drug target in neuroimmune disorders. Mol Neurobiol 50: 1059-1084. doi:10.1007/ s12035-014-8705-x

Mroczek S, Kufel J. 2008. Apoptotic signals induce specific degradation of ribosomal RNA in yeast. Nucleic Acids Res 36: 2874-2888. doi:10.1093/nar/gkm1100

Munoz AM, Yourik P, Rajagopal V, Nanda JS, Lorsch JR, Walker SE. 2017. Active yeast ribosome preparation using monolithic anion exchange chromatography. RNA Biol 14: 188-196. doi:10.1080/ 15476286.2016.1270004

Ochi T. 1996. Menadione causes increases in the level of glutathione and in the activity of $\gamma$-glutamylcysteine synthetase in cultured Chinese hamster V79 cells. Toxicology 112: 45-55. doi:10.1016/ 0300-483X(96)03348-3

Oeffinger M, Wei KE, Rogers R, DeGrasse JA, Chait BT, Aitchison JD, Rout MP. 2007. Comprehensive analysis of diverse ribonucleoprotein complexes. Nat Methods 4: 951-956. doi:10.1038/nmeth1101

Panthu B, Décimo D, Balvay L, Ohlmann T. 2015. In vitro translation in a hybrid cell free lysate with exogenous cellular ribosomes. Biochem J 467: 387-398. doi:10.1042/BJ20141498

Penzo M, Carnicelli D, Montanaro L, Brigotti M. 2016. A reconstituted cell-free assay for the evaluation of the intrinsic activity of purified human ribosomes. Nat Protoc 11: 1309-1325. doi:10.1038/nprot .2016 .072

Pestova TV, Borukhov SI, Hellen CUT. 1998. Eukaryotic ribosomes require initiation factors 1 and $1 \mathrm{~A}$ to locate initiation codons. Nature 394: 854-859. doi:10.1038/29703

Rau M, Ohlmann T, Pain VM, Morley SJ. 1998. A fractionated reticulocyte lysate system for studies on protein synthesis initiation factors. Methods Mol Biol 77: 211-226. doi:10.1385/0-89603-397-X:211

Rijal K, Chow CS. 2009. A new role for cisplatin: probing ribosomal RNA structure. Chem Commun (Camb) 107-109. doi:10.1039/ B816633A

Shao S, Hegde RS. 2014. Reconstitution of a minimal ribosome-associated ubiquitination pathway with purified factors. Mol Cell 55: 880-890. doi:10.1016/j.molcel.2014.07.006
Shcherbik N, Pestov DG. 2019. The impact of oxidative stress on ribosomes: from injury to regulation. Cells 8: 1379. doi:10.3390/ cells8111379

Shedlovskiy D, Shcherbik N, Pestov DG. 2017a. One-step hot formamide extraction of RNA from Saccharomyces cerevisiae. RNA Biol 14: 1722-1726. doi:10.1080/15476286.2017.1345417

Shedlovskiy D, Zinskie JA, Gardner E, Pestov DG, Shcherbik N. 2017b. Endonucleolytic cleavage in the expansion segment 7 of $25 \mathrm{~S}$ rRNA is an early marker of low-level oxidative stress in yeast. J Biol Chem 292: 18469-18485. doi:10.1074/jbc.M117.800003

Shi Z, Fujii K, Kovary KM, Genuth NR, Röst HL, Teruel MN, Barna M. 2017. Heterogeneous ribosomes preferentially translate distinct subpools of mRNAs genome-wide. Mol Cell 67: 71-83.e7. doi:10.1016/j.molcel.2017.05.021

Simms CL, Hudson BH, Mosior JW, Rangwala AS, Zaher HS. 2014. An active role for the ribosome in determining the fate of oxidized mRNA. Cell Rep 9: 1256-1264. doi:10.1016/j.celrep.2014.10.042

Simsek D, Tiu GC, Flynn RA, Byeon GW, Leppek K, Xu AF, Chang HY, Barna M. 2017. The mammalian ribo-interactome reveals ribosome functional diversity and heterogeneity. Cell 169: 10511065.e18. doi:10.1016/j.cell.2017.05.022

Smethurst DGJ, Kovalev N, McKenzie ER, Pestov DG, Shcherbik N. 2020. Iron-mediated degradation of ribosomes under oxidative stress is attenuated by manganese. J Biol Chem 295: 1720017214. doi:10.1074/jbc.RA120.015025

Tanaka M, Chock PB, Stadtman ER. 2007. Oxidized messenger RNA induces translation errors. Proc Natl Acad Sci 104: 66-71. doi:10 .1073/pnas.0609737104

Trainor BM, Ghosh A, Pestov DG, Hellen CUT, Shcherbik N. 2021a. A translation enhancer element from black beetle virus engages yeast elF4G1 to drive cap-independent translation initiation. Sci Rep 11: 2461. doi:10.1038/s41598-021-82025-6

Trainor BM, Komar AA, Pestov DG, Shcherbik N. 2021b. Cell-free translation: preparation and validation of translation-competent extract from Saccharomyces cerevisiae. Bio Protoc 11: e4093. doi:10.21769/BioProtoc.4093

Wu C, Sachs MS. 2014. Preparation of a Saccharomyces cerevisiae cell-free extract for in vitro translation. Methods Enzymol 539: 17-28. doi:10.1016/B978-0-12-420120-0.00002-5

Wu C, Dasgupta A, Shen L, Bell-Pedersen D, Sachs MS. 2018. The cell free protein synthesis system from the model filamentous fungus Neurospora crassa. Methods 137: 11-19. doi:10.1016/j.ymeth .2017.12.003

Yan LL, Simms CL, McLoughlin F, Vierstra RD, Zaher HS. 2019. Oxidation and alkylation stresses activate ribosomequality control. Nat Commun 10: 5611. doi:10.1038/s41467019-13579-3

Zinskie JA, Ghosh A, Trainor BM, Shedlovskiy D, Pestov DG, Shcherbik N. 2018. Iron-dependent cleavage of ribosomal RNA during oxidative stress in the yeast Saccharomyces cerevisiae. J Biol Chem 293: 14237-14248. doi:10.1074/jbc .RA118.004174 



A PUBLICATION OF THE RNA SOCIETY

\section{Development, validation, and application of the ribosome separation and reconstitution system for protein translation in vitro}

Brandon M. Trainor, Dimitri G. Pestov and Natalia Shcherbik

RNA 2021 27: 1602-1616 originally published online August 27, 2021

Access the most recent version at doi:10.1261/rna.078852.121

Supplemental http://rnajournal.cshlp.org/content/suppl/2021/08/27/rna.078852.121.DC1
Material

References This article cites 51 articles, 12 of which can be accessed free at: http://rnajournal.cshlp.org/content/27/12/1602.full.html\#ref-list-1

Open Access Freely available online through the RNA Open Access option.

Creative This article, published in $R N A$, is available under a Creative Commons License Commons (Attribution-NonCommercial 4.0 International), as described at License http://creativecommons.org/licenses/by-nc/4.0/.

Email Alerting Receive free email alerts when new articles cite this article - sign up in the box at the Service top right corner of the article or click here.

To subscribe to RNA go to:

http://rnajournal.cshlp.org/subscriptions

(C) 2021 Trainor et al.; Published by Cold Spring Harbor Laboratory Press for the RNA Society 